\title{
Experimentos de campo com teto-reservatório e painéis para resfriamento radiante em uma edificação-teste
}

\author{
Field experiments with a roof pond and radiant cooling \\ panels in a test building
}

\section{Leandro Carlos Fernandes \\ Eduardo Leite Krüger \\ Wolfgang Motzafi-Haller}

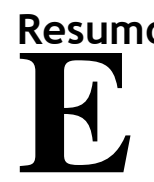

ntre os componentes de uma edificação passiva, a cobertura é particularmente importante para a regulação das condições térmicas internas. Dos sistemas para resfriamento passivo que atuam a partir da cobertura, cita-se o teto-reservatório (TR). Quando o TR é acoplado a painéis radiantes que utilizam água como fluido, pode alcançar alta eficiência energética, potencializando o desempenho da fonte do suprimento de frio. No momento, faltam estudos sobre a aplicação conjunta dessas tecnologias. Esta pesquisa teve como objetivo avaliar os desempenhos térmicos de diferentes configurações de TR, com e sem painéis radiantes, aplicadas a um ambiente de uma edificação-teste no verão. O experimento ocorreu no campus Sde Boqer, da Universidade Ben-Gurion de Negev, em Israel. Como parâmetro para comparação, utilizou-se a cobertura original da edificação-teste. Avaliou-se o desempenho térmico ante as normas Standard 55 e EN 15251, a estabilização das temperaturas internas e o resfriamento. O sistema apresentou bons resultados em se tratando da moderação das condições térmicas externas, especialmente quando considerada a norma europeia EN 15251.

Palavras-chave: Teto-reservatório. Desempenho térmico. Resfriamento evaporativo. Resfriamento radiante.

${ }^{1}$ Leandro Carlos Fernandes ${ }^{1}$ Universidade Federal do Paraná Curitiba - PR - Brasil

${ }^{2}$ Eduardo Leite Krüger 2Universidade Tecnológica Federal do Paraná Curitiba - PR - Brasil

${ }^{3}$ Wolfgang Motzafi-Haller ${ }^{3}$ Ben Gurion University of the Negev Midreshet Ben Gurion, Israel

Recebido em 02/10/19 Aceito em 05/01/20

\begin{abstract}
Among the components of a passive building, the roof is particularly important for the regulation of internal thermal conditions. Among the passive cooling systems that act from the roof, we can mention the roof pond (RP). In turn, radiant panels that use water as fluid can achieve high energy efficiency, enhancing the performance of the cold supply source. However, studies on the joint application of these technologies are lacking. This research study aimed to evaluate the thermal performances of different RP configurations, with and without radiant panels, applied to a test building during the summer. The experiment took place at the Sde Boqer Campus, Ben-Gurion University of Negev, Israel. The test environment with a conventional local roof was used as a parameter for comparison. The thermal performance was evaluated using Standard 55 and EN 15251, stabilisation of internal temperatures, and cooling. Compared to the conventional roof, the RP presented good results in terms of the moderation of the thermal conditions of the test building, especially when considering the European standard EN 15251.
\end{abstract}

Keywords: Roof pond. Thermal performance. Evaporative cooling. Radiant cooling. n. 1, p. 357-384, jan./mar. 2021. 


\section{Introdução}

Um dos objetivos da pesquisa na área do condicionamento térmico de edificações é o desenvolvimento de tecnologias com alto desempenho e baixo consumo energético (FOSSATI et al., 2016). Entre as linhas de pesquisa capazes de prover soluções para essa demanda está a arquitetura passiva, que visa ao conforto térmico sem o consumo de energia elétrica. Quanto aos componentes de uma edificação passiva, são particularmente importantes para a regulação das condições ambientais internas aqueles que constituem a envoltória do edifício: a cobertura, as paredes e as aberturas. Em edificações de poucos pavimentos, destacase o papel da cobertura, pois é através dela que ocorre grande parte das trocas térmicas com o ambiente externo (LAMBERTS, 1988). Em razão disso, investe-se em sistemas passivos com foco nesse elemento da edificação, tais como o teto-reservatório (TR).

O termo "teto-reservatório" denomina sistemas que incorporam na cobertura um reservatório d'água para estocar, trocar ou dissipar calor (ERELL; YANNAS; MOLINA, 2006). O TR pode estar em contato direto com o ambiente abaixo ou separado deste por um forro. Pode propiciar inércia térmica nos períodos de grande amplitude térmica diária e atuar para resfriamento nos períodos quentes e para aquecimento nos frios (HYDE, 2008). Entre as estratégias da arquitetura passiva associadas ao TR destacam-se o resfriamento evaporativo indireto, o resfriamento radiante noturno e a massa térmica para redução da amplitude térmica diária.

Segundo Runsheng, Etzion e Erell (2003), os primeiros estudos acadêmicos sobre o TR ocorreram no Texas, na década de 1920, e abordaram o fluxo de calor em coberturas. Tais experimentos apresentaram problemas devido ao peso dos reservatórios e, por isso, foram interrompidos. Desde então, segundo Overbey (2012), existem dúvidas sobre a efetividade do sistema e dificuldades com sua instalação e manutenção. Citam-se a dificuldade para encaixá-lo em uma categoria, por servir tanto para aquecimento como para resfriamento, a dificuldade para isolar os reservatórios de modo a reduzir as perdas térmicas, os problemas com vazamentos e o peso do corpo d'água para os padrões construtivos dos países onde predominam construções leves. No entanto, Overbey (2012) argumenta que existem soluções técnicas que permitem superar esses problemas e que, diante do alto potencial do sistema, deve-se investir nas pesquisas.

As primeiras revisões bibliográficas a respeito do TR apresentaram poucos títulos e enfocaram reservatórios de concreto (TIWARI; KUMAR; SODHA, 1982; GIVONI, 2011). Com o aumento do interesse pelo tema, revisões posteriores apresentaram TR de diversas configurações e de diferentes materiais (SPANAKI; TSOUTSOS; KOLOKOTSA, 2011; SHARIFI; YAMAGATA, 2015).

Entre as novas abordagens, busca-se potencializar o resfriamento evaporativo e explorar o resfriamento radiante utilizando reservatórios metálicos (GONZÁLEZ-CRUZ, 1997; TÉPOX; GONZÁLEZ-CRUZ; MATA, 2008; GONZÁLEZ-CRUZ; GONZÁLEZ-GARCIA, 2013) em vez de reservatórios de concreto. A maior condutividade térmica dos reservatórios metálicos (GONZÁLEZ-CRUZ, 1997) permite reduzir a diferença entre as temperaturas da água do reservatório e do ar do ambiente abaixo, comparativamente ao uso de reservatórios de concreto (CHÁVEZ; GIVONI; MUNDET, 2007). Recentemente, utilizando equações preditivas, avaliou-se a aplicabilidade do TR metálico em 411 cidades brasileiras. Os resultados indicaram redução das médias das temperaturas internas na maioria das cidades, entre $-0,8{ }^{\circ} \mathrm{C}$ e $-2,5^{\circ} \mathrm{C}$ (GONZÁLEZ-CRUZ; KRÜGER; GIORDANO, 2014). TR metálicos também foram aplicados aos climas das regiões de Florianópolis e Curitiba em pesquisas com células-teste, nas quais as médias das temperaturas internas do ar também apresentaram redução de aproximadamente $2{ }^{\circ} \mathrm{C}$ em comparação com as médias externas (GONZÁLEZ-CRUZ et al., 2014; KRÜGER; FERNANDES; LANGE, 2016; KRÜGER et al., 2016).

Paralelamente às pesquisas com TR, avançam os estudos com sistemas de aquecimento e resfriamento radiante (RHEE; KIM, 2015). Uma alternativa para melhorar o desempenho dos reservatórios de concreto é acoplá-los a sistemas de resfriamento radiante tendo água como fluido, reduzindo as perdas térmicas (LI et al., 2015). Nesse caso, o TR atuaria como fonte do fluido resfriado, e os painéis radiantes metálicos atuariam como trocadores de calor. Há evidências de que sistemas de resfriamento radiante podem propiciar condições de conforto iguais ou melhores que sistemas de ar-condicionado convencionais (KARMANN; SCHIAVON; BAUMAN, 2017). Segundo a ASHRAE (AMERICAN..., 2012), em sistemas de aquecimento e resfriamento radiante, a transferência de calor radiante cobre mais de $50 \%$ das trocas de calor dentro do espaço condicionado. Ainda, segundo Szokolay (2008), em climas quentes, onde predomina o uso de roupas leves, a temperatura radiante média é duas vezes mais influente para a sensação térmica que a temperatura do ar. Testes em uma edificação-experimental dotada de painéis de resfriamento radiante mostraram que dois terços do resfriamento de verão ocorreram por radiação, e apenas um terço por convecção (MIRIEL;

358 Fernandes. L. C.; Krüger, C. E.; Motzafi-Haller, W. 
SERRES; TROMBE, 2002). Imanari, Omori e Bogaki (1999) compararam as percepções térmicas de usuários submetidos a dois modos de resfriamento em uma sala de reuniões: com um painel radiante suspenso no teto; e com uma unidade de ar condicionado. Embora as condições térmicas fossem equivalentes, o resfriamento radiante gerou uma porcentagem maior de votos de conforto. Meggers et al. (2017) apresentaram um estudo com voluntários em um pavilhão experimental semifechado com sistema de resfriamento evaporativo indireto e painéis radiantes (PR) com serpentinas resfriadas. Em um dia de verão, embora as temperaturas internas e externas do ar fossem similares, a maior parte dos participantes estimou temperaturas internas inferiores às externas.

Entre as pesquisas listadas que abordaram resfriamento radiante, nenhuma utilizou TR ou resfriamento estrutural. Surge, então, a hipótese de que é possível potencializar o desempenho do TR de concreto se este for acoplado a painéis radiantes instalados no interior da edificação, resultando em um sistema híbrido, possivelmente equivalente ao TR metálico.

Tendo em vista as questões apresentadas, o objetivo desta pesquisa foi avaliar o desempenho térmico de diferentes configurações de TR para resfriamento (com e sem painéis radiantes) aplicadas a uma edificaçãoteste.

\section{Procedimentos metodológicos}

Visando ao objetivo da pesquisa, a partir da cobertura original da edificação-teste, foram propostas diferentes configurações para o sistema de resfriamento, implantadas uma após a outra, sempre sobre o mesmo ambiente. A configuração original da cobertura foi adotada como parâmetro para avaliar as demais. Para viabilizar as comparações, foi adotado um método preditivo para estimar as temperaturas horárias da configuração original nos momentos em que eram testadas as configurações alternativas.

A alternância de configurações visou avaliar os efeitos de alterações no sombreamento, no isolamento térmico, na exposição ao céu noturno (perdas radiantes), na circulação da água e na exposição desta à evaporação. Os resultados foram analisados com base nas normas EN 15251 (EUROPEAN..., 2007) e Standard 55 (AMERICAN..., 2017), na carta bioclimática adaptada por Bogo et al. (1994) e nos índices de desempenho fator decremental $(f)$ e coeficiente de dissemelhança (CD).

\section{Clima local}

O campus Sde Boqer está a $478 \mathrm{~m}$ acima do nível do mar, no sul de Israel $\left(30,8^{\circ} \mathrm{N}, 35^{\circ} \mathrm{L}\right)$, no deserto de Negev (ISRAEL..., 2007). A precipitação média anual local é de $93 \mathrm{~mm}$ (IMS, 2012). O clima apresenta grandes flutuações térmicas diárias e sazonais, ar seco e céu limpo com radiação solar intensa. No verão, a média das temperaturas diárias máximas é $32^{\circ} \mathrm{C}$, e a das mínimas é $17^{\circ} \mathrm{C}$. A radiação global é de 7,7 $\mathrm{kWh} / \mathrm{m}^{2}$ por dia durante junho e julho. No inverno, os dias normalmente são ensolarados. A média das temperaturas diárias máximas é de $14,9^{\circ} \mathrm{C}$, e a das mínimas é de $3,8{ }^{\circ} \mathrm{C}$ (BITAN; RUBIN, $1991^{1}$ apud KRÜGER; GONZÁLEZ-CRUZ; GIVONI, 2010). Na classificação de Köppen-Geiger, a região é uma área de transição entre os climas BWh (das regiões desérticas quentes de baixa latitude e altitude), ao sul, e BSh (das estepes quentes de baixa latitude e altitude), ao norte (KOTTEK et al., 2006; RUBEL et al., 2017). Os meses de junho a setembro, de interesse para este estudo, apresentam altas temperaturas e pouquíssima precipitação.

\section{Análise dos dados climáticos locais}

$\mathrm{Na}$ análise do clima, foram utilizados dados de base horária, registrados em estação meteorológica do campus no ano de 2006 e disponibilizados no formato Test Reference Year (TRY). A análise teve como foco produzir elementos que pudessem subsidiar a elaboração do experimento. Obtiveram-se resumos das estatísticas descritivas das variáveis temperatura do ar $\left(T_{a}\right)$, umidade relativa $(U R)$ e amplitude térmica diária $\left(\Delta T_{a}\right)$, e realizou-se a plotagem das variáveis $T_{a}$ e $U R$ sobre a carta bioclimática adaptada por Bogo et al. (1994).

As temperaturas do ar também possibilitaram definir as faixas de conforto para edificações condicionadas naturalmente segundo as normas EN 15251 (EUROPEAN..., 2007) e Standard 55 (AMERICAN..., 2013).

${ }^{1}$ BITAN, A.; RUBIN, S. Climatic Atlas of Israel for Physical Planning and Design. Israel Meteorological Service and Ministry of Energy and Infrastructure, 1991. 
As faixas definidas por essas normas também foram utilizadas nas análises de desempenho térmico das configurações testadas.

A análise do clima com enfoque nas amplitudes térmicas diárias tomou como referência a amplitude térmica diária $\left(\Delta T_{a \text { in }}\right)$ máxima aceitável para a faixa de aceitabilidade térmica contemplando $80 \%$ da população (7 ${ }^{\circ} \mathrm{C}$ ) da Standard 55 (AMERICAN..., 2017).

\section{Edificação experimental}

A edificação-teste foi construída em 1991 e projetada como uma residência unifamiliar térrea, com três quartos, uma cozinha, sala de jantar e banheiro (ERELL; KAFTAN; MOTZAFI-HALLER, 2011), conforme as Figuras 1 e 2.

Nesse experimento foi utilizado o quarto na extremidade leste da edificação (Figura 2). O teto (laje de concreto com $10 \mathrm{~cm}$ de espessura) e as faces internas das paredes foram pintados de branco (refletância 0,75), enquanto o piso foi revestido com granitina (refletância 0,45) (ERELL et al., 1992). A parede sul tem uma janela em alumínio com 1,34 $\mathrm{m}$ de largura por 1,76 $\mathrm{m}$ de altura, dotada de persiana externa de PVC branco, que permaneceu parcialmente levantada $(50 \mathrm{~cm})$ para propiciar iluminação natural, e de brises verticais externos. A parede norte apresenta uma pequena janela, que permaneceu com vidro e persiana externa fechados.

Figura 1 - Vista frontal da edificação-teste (orientação sul)

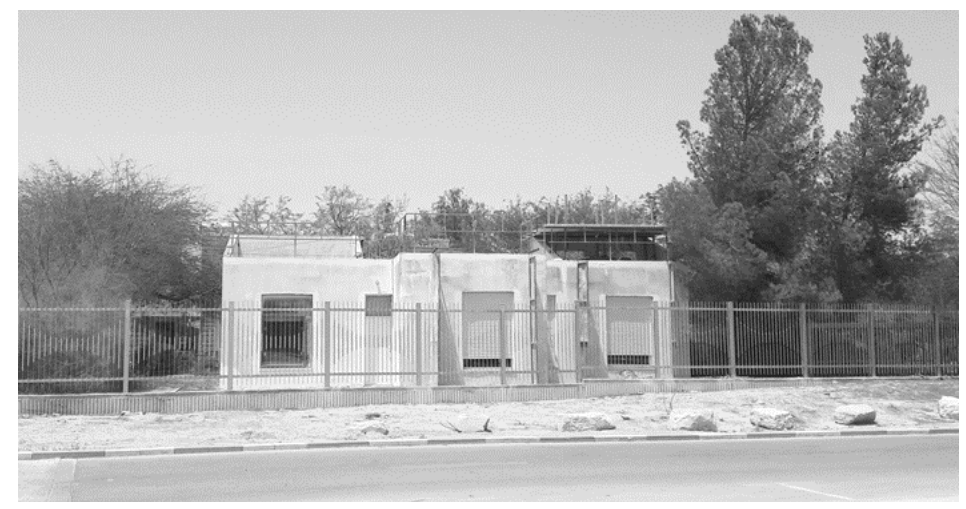

Figura 2 - Planta baixa da edificação-teste

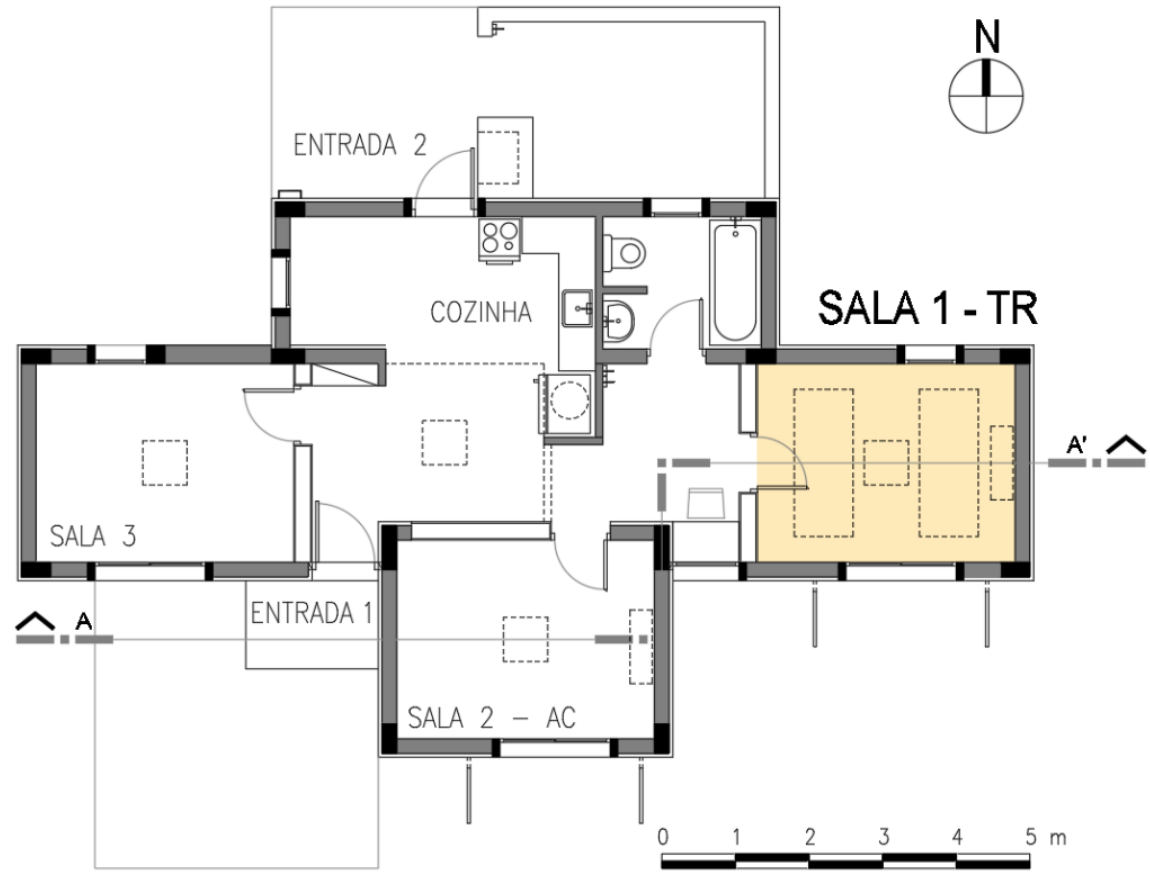

360 Fernandes. L. C.; Krüger, C. E.; Motzafi-Haller, W. 


\section{Configurações da cobertura}

A seguir são descritas as oito configurações de cobertura monitoradas. As duas primeiras não apresentaram TR e foram inseridas para fins de comparação.

(a) Configuração 1 (configuração controle - CC): cobertura original, constituída de laje de concreto com $10 \mathrm{~cm}$ de espessura, regularizada, impermeabilizada, revestida $\mathrm{com} 3 \mathrm{~cm}$ de argamassa e pintada de branco (Figura 3);

(b) Configuração 2: acrescentaram-se à cobertura telhas de PVC branco (policloreto de vinil), com $2 \mathrm{~mm}$ de espessura, a 1,5 m acima da laje, provendo sombra e livre ventilação;

(c) Configuração 3: adicionou-se uma piscina de plástico branco, caracterizando o TR. A piscina foi preenchida com $755 \mathrm{~L}$ d'água, com $8,7 \mathrm{~cm}$ de profundidade e $8,64 \mathrm{~m}^{2}$ de área exposta ao resfriamento evaporativo. Manteve-se o nível, repondo-se a água evaporada diariamente, pela manhã, quando as temperaturas externas eram mais baixas. Também foi ativada uma bomba d'água, forçando a circulação entre o TR e dois painéis radiantes de alumínio instalados no teto do ambiente abaixo. Os painéis mediam 2 $\mathrm{m} \times 0,8 \mathrm{~m}$ cada $\left(1,6 \mathrm{~m}^{2}\right)$ e possuíam serpentinas pelas quais circulava a água bombeada. A absorção do calor ambiente ocorria por convecção e por absorção da radiação de ondas longas;

(d) Configuração 4: foi adicionada, sobre a lâmina d'água, uma camada flutuante de EPS (placas medindo $50 \mathrm{~cm} \times 100 \mathrm{~cm} \times 6 \mathrm{~cm}$ ). A área total coberta pelo EPS era de $8 \mathrm{~m}^{2}$, restando $0,64 \mathrm{~m}^{2}$ de água exposta à evaporação;

(e) Configuração 5: acrescentou-se spray noturno (das $17 \mathrm{~h} 45$ às $8 \mathrm{~h} 30$ do dia seguinte). $\mathrm{O}$ spray foi instalado abaixo da cobertura;

(f) Configuração 6: os sprays passaram a funcionar $24 \mathrm{~h}$, todos os dias (Figura 3);

(g) Configuração 7: a circulação d'água TR/painéis radiantes foi desativada; e

(h) Configuração 8: retirou-se a camada de EPS flutuante, aumentando a superfície de água exposta à evaporação e se reiniciou a circulação de água pelos painéis radiantes.

A Tabela 1 apresenta resumo das características das configurações e os períodos monitorados considerados neste artigo.

\section{Aquisição de dados}

Os dados relativos às condições externas foram obtidos da estação meteorológica do campus ( $800 \mathrm{~m}$ ao norte da edificação-teste). Foram fornecidas as variáveis temperatura de bulbo seco $\left(T_{a}\right)$, velocidade do ar $\left(v_{a}\right)$, radiação solar global $(R)$ e umidade relativa $(U R)$.

Figura 3 - Corte AA' (configurações 1 e 6) e elevação parcial
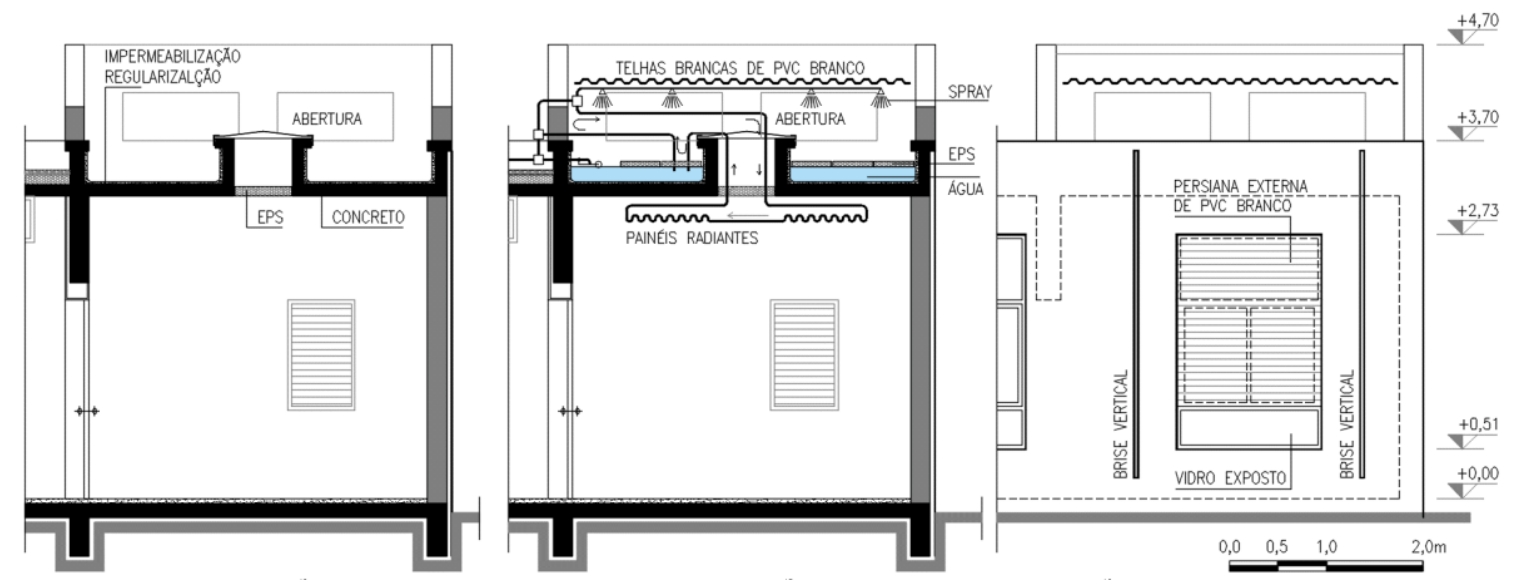

Experimentos de campo com teto-reservatório e painéis para resfriamento radiante em uma edificação-teste 
Tabela 1 - Resumo das características das configurações

\begin{tabular}{|c|c|c|c|c|c|c|c|c|}
\hline $\begin{array}{c}\text { Configura- } \\
\text { ção }\end{array}$ & $\begin{array}{c}\text { Sombrea- } \\
\text { mento }\end{array}$ & $\begin{array}{c}\text { Nível de } \\
\text { água }(\mathrm{cm})\end{array}$ & $\begin{array}{c}\text { Isolamento } \\
\text { flutuante }\end{array}$ & $\begin{array}{c}\text { Circulação } \\
\text { forçada nos } \\
\text { painéis radiantes } \\
\end{array}$ & $\begin{array}{c}\text { Spray } \\
\text { diurno }\end{array}$ & $\begin{array}{c}\text { Sprays } \\
24 \mathrm{~h}\end{array}$ & Período & $\begin{array}{c}\text { Total } \\
\text { de dias }\end{array}$ \\
\hline $\begin{array}{l}\text { Configuração } \\
1 \text { (controle - } \\
\text { CC) }\end{array}$ & - & - & - & - & - & - & $\begin{array}{c}16 / 06 \text { a } \\
24 / 06 / 17\end{array}$ & 9 \\
\hline $\begin{array}{l}\text { Configuração } \\
2\end{array}$ & Sim & - & - & - & - & - & $\begin{array}{c}26 / 06 \mathrm{a} \\
05 / 07 / 17\end{array}$ & 10 \\
\hline $\begin{array}{l}\text { Configuração } \\
3\end{array}$ & Sim & 8,7 & - & Sim & - & - & \begin{tabular}{|c|}
$10 / 07 \mathrm{a}$ \\
$18 / 07 / 17$
\end{tabular} & 9 \\
\hline $\begin{array}{l}\text { Configuração } \\
4\end{array}$ & Sim & 8,7 & Sim & Sim & - & - & \begin{tabular}{|c|}
$20 / 07 \mathrm{a}$ \\
$25 / 07 / 17$
\end{tabular} & 6 \\
\hline $\begin{array}{l}\text { Configuração } \\
5\end{array}$ & Sim & 8,7 & Sim & Sim & Sim & - & \begin{tabular}{|c|}
$26 / 07 \mathrm{a}$ \\
$28 / 07 / 17$
\end{tabular} & 3 \\
\hline $\begin{array}{l}\text { Configuração } \\
6\end{array}$ & Sim & 8,7 & Sim & Sim & - & Sim & \begin{tabular}{|c|}
$29 / 07 \mathrm{a}$ \\
$07 / 08 / 17$
\end{tabular} & 10 \\
\hline $\begin{array}{l}\text { Configuração } \\
7\end{array}$ & Sim & 8,7 & Sim & - & - & Sim & \begin{tabular}{|c|}
$28 / 08 \mathrm{a}$ \\
$04 / 09 / 17$
\end{tabular} & 8 \\
\hline $\begin{array}{l}\text { Configuração } \\
8\end{array}$ & Sim & 8,7 & - & Sim & - & Sim & $\begin{array}{c}10 / 09 \mathrm{a} \\
14 / 09 / 17 \\
\end{array}$ & 4 \\
\hline TOTAL & & & & & & & & 59 \\
\hline
\end{tabular}

A instalação dos sensores na edificação-teste (Figuras 4 e 5) seguiu orientações da norma ISO 7726 (INTERNATIONAL..., 1998). Os dados eram registrados em uma central data logger (Campbell Scientific Datalogger CR23X), à qual foi conectada uma interface (Campbell Scientific Multiplexer AM-32) para ampliar o número de entradas. Foram conectados à interface 18 sensores de temperatura (termopares do tipo T). Destes, 15 foram instalados internamente: quatro medindo $T_{a}$ em diferentes alturas $(0,1 \mathrm{~m}, 0,6 \mathrm{~m}, 1,1 \mathrm{~m}$ e $2,8 \mathrm{~m}$ ), um medindo a temperatura de globo $\left(T_{g}\right)$ a $0,6 \mathrm{~m}$ de altura, e dez medindo temperaturas superficiais $\left(T_{S}\right)$ (seis no teto, piso e paredes, dois nos painéis radiantes, e dois nos vidros da janela principal). Sobre a cobertura foram instalados três sensores do tipo T: dois para monitorar a temperatura da água e um para medir a $T_{a}$. Também foi conectada à interface uma sonda de temperatura e umidade da marca Vaisala, modelo HMP60, a 0,6 m de altura, para medir $T_{a}$ e $U R$. Para todos os sensores, eram realizadas leituras a cada $30 \mathrm{~s}$ e gravadas as médias a cada $10 \mathrm{~min}$.

\section{Pós-processamento dos dados}

Para melhor entendimento do comportamento de cada configuração, além de utilizados dados médios, analisaram-se, comparativamente, dias específicos. Deu-se preferência para dias de céu claro e com grande $\Delta T_{a \text { in }}$ diária. Para a escolha desses dias, calculou-se um coeficiente denominado dia padrão (DP). Os dias de cada período com maior valor para esse coeficiente foram usados nas comparações. Os valores dos coeficientes DP foram calculados utilizando-se a Equação 1.

$D P=\left(T_{7 h}-T_{14 h}\right)-\left|\left(T_{7 h}-T_{31 h}\right)\right|$

Eq. 1

Em que:

$D P$ é o coeficiente de referência;

$T_{7 h}$ a temperatura às $7 \mathrm{~h}$ daquele dia;

$T_{14 h}$ a temperatura às $14 \mathrm{~h}$ daquele dia; e

$T_{31 h}$ a temperatura às $7 \mathrm{~h}$ do dia seguinte.

A temperatura radiante média $\left(T_{r m}\right)$ foi obtida de forma indireta, conforme a norma ISO 7726 (INTERNATIONAL..., 1998), utilizando-se o fator de forma $\left(F_{i}\right)$ e as temperaturas superficiais $\left(T_{s}\right)$. Esse método leva em conta um ponto de interesse na sala (posição dos sensores) e dá mais importância para as $T_{S}$ das superfícies que apresentarem os maiores ângulos sólidos em relação a esse ponto (ROMANA et al., 2013). O ângulo sólido $(\Omega)$ é um conceito geométrico que informa o tamanho aparente de um objeto quando 
visto a partir de um ponto. Corresponde à área da projeção do objeto sobre uma esfera (de raio 1) cujo centro é o referido ponto de interesse (SOLDOVIERI; VILORIA, 2016). Dada uma sala de planta retangular e um ponto de interesse, a soma dos ângulos sólidos das superfícies que a delimitam será igual à área de uma esfera, dada em esferorradianos ( $4 \pi$ ou 12,566). Tomando-se uma superfície (parede, por exemplo) como a base de uma pirâmide e o ponto de interesse como seu vértice, pode-se estimar o ângulo sólido definido por essa superfície com a Equação 2 (FERNÁNDEZ-GONZÁLEZ; COSTACHE, 2012):

$\Omega=4 \tan ^{-1}\left(\frac{\mathrm{ab}}{2 \mathrm{~d}\left(4 \mathrm{~d}^{2}+\mathrm{a}^{2}+\mathrm{b}^{2}\right)^{0,5}}\right)$

Eq. 2

Em que:

$\Omega_{\mathrm{i}}$ é o ângulo sólido dado pela superfície em relação ao ponto de interesse;

a o comprimento da base da pirâmide;

b a largura da base da pirâmide; e

d a distância entre o centro da base e o topo da pirâmide.

$O$ fator de forma (F) (Equação 3) corresponde ao ângulo sólido relativo em torno de um ponto (FERNÁNDEZ-GONZÁLEZ; COSTACHE, 2012):

$F_{i}=\frac{\Omega_{i}}{4 \pi}$

Eq. 3

Figura 4 - Planta baixa com as posições dos sensores

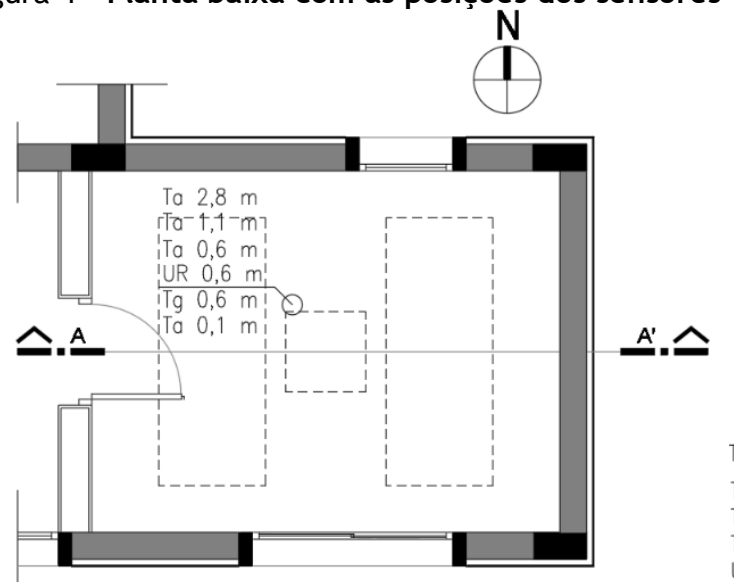

TIPOS DE SENSORES

To = TEMPERATURA DO AR

TS = TEMPERATURA SUPERFICIAL

$\mathrm{Tg}=$ TEMPERATURA DE GLOBO

UR = UMIDADE RELATIVA

Figura 5 - Corte com as posições dos sensores (configuração 6)

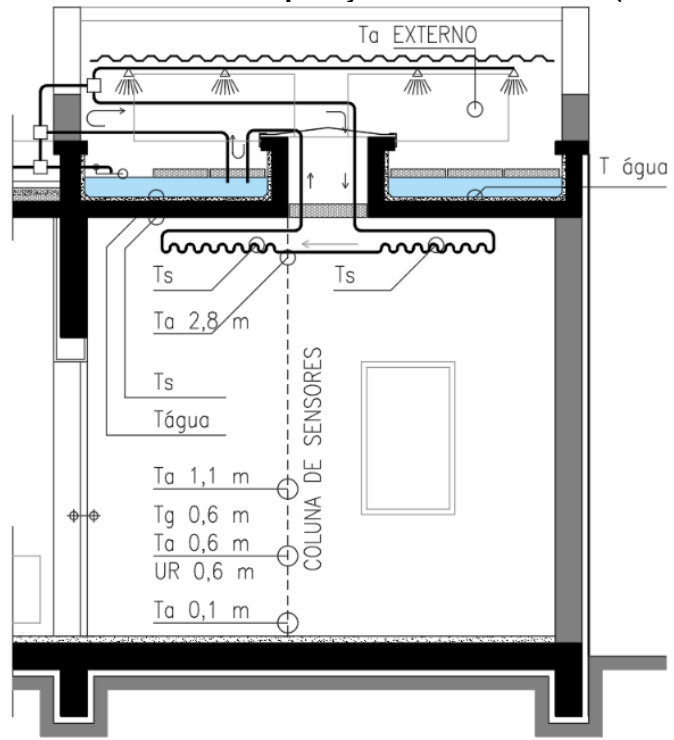

TIPOS DE SENSORES

TO = TEMPERATURA DO AR

TS = TEMPERATURA SUPERFICIAL

$g=$ TEMPERATURA DE GLOBO

UR = UMIDADE RELATIVA

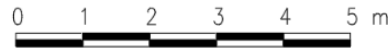

Experimentos de campo com teto-reservatório e painéis para resfriamento radiante em uma edificação-teste 
A $T_{r m}$ é estimada por esse método tendo em conta as $T_{s}$ das superfícies internas (teto, piso, paredes, vidros e painéis radiantes) e seus respectivos fatores de forma (Equação 4) (FERNÁNDEZ-GONZÁLEZ; COSTACHE, 2012):

$T_{r m}=\sum\left(F_{i} T_{s}\right)$

Eq. 4

\section{Estimativa de temperaturas internas horárias}

Neste trabalho, optou-se pela análise comparativa, relacionando o desempenho da CC com o das demais configurações. $\mathrm{O}$ método preditivo de temperaturas internas horárias permitiu trabalhar com apenas uma edificação em vez de várias edificações-teste monitoradas simultaneamente. Os procedimentos relativos ao método preditivo são apresentados em detalhe em Krüger et al. (2017). O modelo estima a variação da temperatura interna horária $\left(\Delta T_{i n}\right)$ como função da diferença entre a temperatura interna horária em dado momento $\left(T_{i n}^{t-1}\right)$ e a temperatura externa horária no momento seguinte $\left(T_{e x}^{t}\right)$. Somando-se essa estimativa de variação da temperatura, no intervalo de $1 \mathrm{~h}$ (de $t-1$ para $t)$, com a temperatura interna da hora anterior à variação $(t-1)$, tem-se a estimativa da temperatura interna horária para o momento $t$ (Equação 5).

$T_{a \text { in }}^{t}=T_{a \text { in }}^{t-1}+\alpha\left(T_{a \text { ex }}^{t}-T_{a \text { in }}^{t-1}\right)$

Eq. 5

Em que:

$T_{a \text { in }}^{t}$ é a temperatura interna $\left({ }^{\circ} \mathrm{C}\right)$ estimada no instante $t$;

$T_{\text {a in }}^{t-1}$ a temperatura interna $\left({ }^{\circ} \mathrm{C}\right)$ estimada ou medida no instante $t-1$;

$T_{a \text { ex }}^{t}$ a temperatura externa $\left({ }^{\circ} \mathrm{C}\right)$ medida no instante $t$; e

$\alpha$ uma função que descreve a variação proporcional da temperatura interna em função da diferença entre $T_{e x}^{t-n}$ e $T_{i n}^{t-1}$.

Os valores médios de $\alpha$ determinam como a edificação se relaciona com a temperatura externa (Equação 6):

$\alpha=\frac{T_{a i n}^{t}-T_{a}^{t-1}}{T_{a}^{t} \text { ex }-T_{a \text { in }}^{t-1}}$

Quanto mais a diferença entre a temperatura externa $\left(T_{e x}^{t}\right)$ e a temperatura interna $\left(T_{i n}^{t-1}\right)$ se afastar de zero, mais os valores de $\alpha$ tenderão a se estabilizar em torno de dois valores médios:

(a) um valor médio para quando predominarem as perdas térmicas do ambiente interno para o ambiente externo, denominado " $\alpha$ médio para perdas"; e

(b) outro valor médio para quando predominarem os ganhos térmicos, denominado " $\alpha$ médio para ganhos".

O uso do modelo preditivo contempla três etapas:

(a) calibração;

(b) validação; e

(c) aplicação.

\section{Parâmetros para análise dos dados do ambiente experimental}

Nas análises de desempenho térmico, foram consideradas as faixas de temperaturas operativas $\left(T_{o}\right)$ aceitáveis dadas pelas normas EN 15251 (EUROPEAN..., 2007) e Standard 55 (AMERICAN..., 2017) e a faixa de conforto dada pela carta bioclimática adaptada por Bogo et al. (1994). O cálculo da $T_{o}$ demanda a utilização da $T_{r m}$. Quando a $v_{a}$ no ambiente for menor que $0,2 \mathrm{~m} / \mathrm{s}$, a $T_{o}$ pode ser tomada como a média entre a $T_{r m}$ e a $T_{a}$ (INTERNATIONAL..., 1998). Na maior parte do tempo, a $v_{a}$ no interior da sala foi próxima de zero. Quando maior, variou entre $0,0 \mathrm{~m} / \mathrm{s}$ e $0,2 \mathrm{~m} / \mathrm{s}$. Neste trabalho, considerou-se a hipótese de que a $T_{r m}$ seria praticamente igual à $T_{a}$. Sendo assim, a $T_{o}$ também teria valor muito próximo do da $T_{a}$. Essa hipótese foi verificada e é apresentada na seção dos resultados.

A norma europeia EN 15251 (EUROPEAN..., 2007), para edificações naturalmente ventiladas, adota uma faixa de conforto variável conforme as médias das temperaturas externas diárias. A faixa é definida em torno de uma temperatura operativa neutra $\left(T_{\text {o conf }}\right)$ (Equação 7) (NICOL; HUMPHREYS, 2010):

$T_{\text {o conf }}=0,33 T_{\text {ex méd ep }}+18,8^{\circ} \mathrm{C}$

Eq. 7

364 Fernandes. L. C.; Krüger, C. E.; Motzafi-Haller, W. 
Em que $T_{\text {ex méd ep }}$ é a temperatura externa média exponencialmente ponderada, que pode ser calculada pela Equação 8 (EUROPEAN..., 2007):

$T_{\text {ex méd ep }}=(1-\beta) \times T_{\text {ex méd }-1}+\beta \times T_{\text {ex méd ep }-1}$

Eq. 8

Em que:

$\beta$ é uma constante - recomenda-se utilizar 0,8 (EUROPEAN..., 2007);

$T_{\text {ex méd }-1}$ temperatura externa média do dia anterior $\left({ }^{\circ} \mathrm{C}\right)$; e

$T_{\text {ex méd ep }-1}$ temperatura externa média exponencialmente ponderada calculada para o dia anterior.

Para "novas construções e reformas com expectativa normal", a faixa possui intervalo de $6{ }^{\circ} \mathrm{C}$ (NICOL; WILSON, 2010). Nesse caso, quando a $T_{\text {ex méd ep }}$ apresentar valores inferiores a $10^{\circ} \mathrm{C}$, o limite superior é $26^{\circ} \mathrm{C}$, e o limite inferior é $20^{\circ} \mathrm{C}$ (EUROPEAN..., 2007).

A norma Standard 55 (AMERICAN..., 2017) também adota faixa de conforto variável, definida a partir da média aritmética móvel das temperaturas externas $\left(T_{\text {ex méd } m}\right)$. É aplicável apenas quando as temperaturas médias mensais forem maiores ou iguais a $10{ }^{\circ} \mathrm{C}$ e menores ou iguais a $33,5^{\circ} \mathrm{C}$. A $T_{\text {o conf }}$ é calculada pela Equação 9 (NICOL; HUMPHREYS, 2010).

$T_{\text {o conf }}=0,31 T_{\text {ex méd } m}+17,8^{\circ} \mathrm{C}$

Eq. 9

A $T_{\text {ex méd } m}$ deve basear-se em não menos do que 7 e não mais do que 30 dias consecutivos anteriores ao dia em questão (AMERICAN..., 2017). Em torno da $T_{\text {o conf }}$, foi definida a faixa de aceitabilidade térmica com 7 ${ }^{\circ} \mathrm{C}$ de intervalo, para atendimento de $80 \%$ da população.

Para avaliar a capacidade das configurações de resistir às flutuações das temperaturas internas, foi adotado o índice Fator Decremental $(f)$. O $f$ é descrito como a amplitude térmica diária relativa. Mede a proporção entre as amplitudes térmicas diárias interna e externa (Equação 10) (KRÜGER; GONZÁLEZ-CRUZ; GIVONI, 2010).

$f=\frac{A_{\text {in }}}{A_{\text {ex }}}$

Em que:

$A_{\text {in }}$ é a amplitude térmica diária interna; e

$A_{\text {ex }}$, a externa.

Foi considerado como ótimo o $f$ que atenda à seguinte expressão (Equação11):

$F_{\text {ótimo }} \leq \frac{7^{\circ} \mathrm{C}}{A_{\text {ex máx }}}$

Em que $A_{\text {ex máx }}$ é a amplitude térmica externa máxima. $\mathrm{O}$ valor $7{ }^{\circ} \mathrm{C}$ foi definido na seção "análise com enfoque na amplitude térmica diária".

Para avaliar o desempenho quanto ao resfriamento ou aquecimento, foi utilizado o coeficiente de dissemelhança das temperaturas média diárias (CD). O CD deve ser medido em períodos estáveis. Pode ser entendido como a taxa relativa de aquecimento ou resfriamento, pois mede o deslocamento da temperatura média diária interna em relação à temperatura média diária externa (KRÜGER et al., 2018). Tomando como referência uma edificação hipotética, na qual não operam artifícios para aquecimento ou resfriamento, a

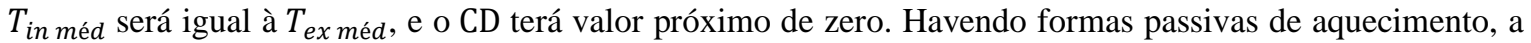
$T_{\text {in méd }}$ será mais alta que a $T_{\text {ex méd }}$, e o CD será maior que zero. Caso o $C D$ alcance valores próximos de 1 , as temperaturas internas médias estarão próximas das externas máximas. Havendo formas passivas de resfriamento, o CD ficará abaixo de zero. Valores próximos de -1 indicam que as temperaturas internas médias se aproximam das mínimas externas. O $C D$ é calculado de acordo com a Equação 12:

$C D=\left(\frac{T_{\text {in méd }}-T_{\text {ex mín }}}{T_{\text {ex méd }}-T_{\text {ex mín }}}\right)-1$

Eq. 12

Experimentos de campo com teto-reservatório e painéis para resfriamento radiante em uma edificação-teste 


\section{Resultados}

\section{Estimativa de temperaturas internas horárias para a configuração controle}

A fim comparar o desempenho da configuração controle (CC) com o desempenho das demais configurações, foram estimadas as temperaturas internas horárias da CC para os períodos correspondentes a cada uma das outras configurações testadas. Para a calibração do modelo, foram utilizados os dois primeiros dias de monitoramento válidos da CC (dias 16 e 17 de junho de 2017). Os valores médios finais de $\alpha$ foram:

(a) 0,0235 quando a $T_{a \text { ex }}$ estava acima da $T_{a \text { in }}$; e

(b) 0,0095 quando a $T_{a \text { ex }}$ estava abaixo da $T_{a \text { in }}$.

Para verificação da precisão das estimativas foram utilizados os 7 dias restantes (de 18 a 24 de junho). Relacionando temperaturas internas horárias medidas e estimadas, obteve-se $\mathrm{R}^{2}=0,9$. A diferença máxima entre as temperaturas internas horárias medidas e as estimadas foi de $0,58{ }^{\circ} \mathrm{C}$, e a diferença média, de 0,25 ${ }^{\circ} \mathrm{C}$ (Figura 6).

Os resultados avalizaram a aplicação do método preditivo. Com o modelo calibrado, foi possível estimar o comportamento da $T_{a \text { in }}$ da $\mathrm{CC}$ nos períodos em que a sala 1 recebeu coberturas com configurações diferentes da configuração original.

\section{Análise do clima local e do desempenho térmico estimado da CC ao longo do ano de referência}

As análises apresentadas nesta subseção tiveram como objetivo subsidiar a elaboração dos experimentos.

$\mathrm{O}$ resumo da estatística descritiva das variáveis $T_{a \text { ex }}$ e $U R$ apresentou temperaturas médias confortáveis, mas grande amplitude térmica anual $\left(41,40{ }^{\circ} \mathrm{C}\right)$, com mínima de $-0,50{ }^{\circ} \mathrm{C}$ e máxima de $40,90{ }^{\circ} \mathrm{C}$, indicando que o clima demanda soluções tanto em relação ao calor quanto em relação ao frio.

O resumo da estatística descritiva da variável amplitude térmica diária do ano climático indicou amplitude térmica diária média de $12,22^{\circ} \mathrm{C}$. Somente $15,62 \%$ dos dias apresentaram amplitude menor ou igual a $7^{\circ} \mathrm{C}$. Amplitudes entre $11^{\circ} \mathrm{C} \mathrm{e} 17{ }^{\circ} \mathrm{C}$ foram comuns, e as próximas de $14{ }^{\circ} \mathrm{C}$ as mais frequentes. Tais resultados indicam que são necessárias estratégias para estabilização das temperaturas internas.

Dados do ano todo (TRY) e do período de verão (Figura 7) foram plotados sobre a carta bioclimática adaptada por Bogo et al. (1994). Nos dois períodos, o número de horas na condição de desconforto predominou sobre o número de horas em conforto (Tabela 2). Quando considerado o ano todo, predominou o desconforto por frio $(49,8 \%)$, e, quando considerado apenas o verão, predominou o desconforto por calor $(53,8 \%)$. Isoladamente, o resfriamento evaporativo é de pouca importância, tanto no ano todo (2,9\%) quanto no verão $(5 \%)$. Quando é considerado em associação com a ventilação e com a alta inércia térmica, é recomendado em $9,6 \%$ do ano e em $23,1 \%$ do verão. Somando-se as porcentagens de tempo (uso isolado + uso em associação com outra estratégia), o resfriamento evaporativo é recomendado em 12,5\% do ano e em $28,1 \%$ do verão, ou seja, o teto-reservatório é uma alternativa adequada para Sde Boqer. Outras estratégias fortemente indicadas para o período de verão foram ventilação e alta inércia térmica (Tabela 2).

Figura $6-\mathbf{T}_{\mathbf{a} \text { in }}$ medida $\times \mathbf{T}_{\mathbf{a} \text { in }}$ estimada para a $\mathrm{CC}$

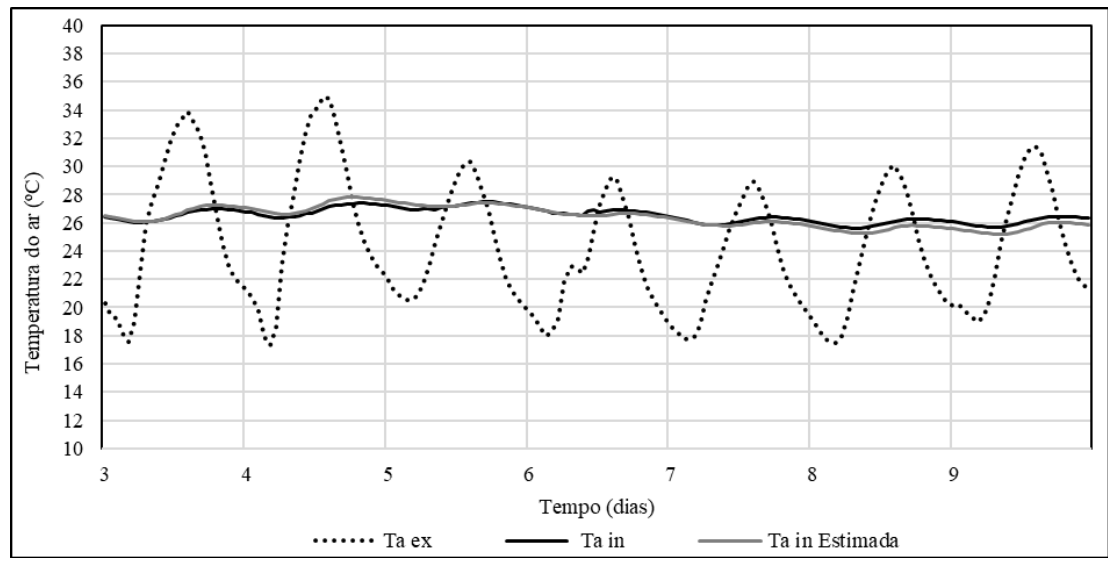

366 Fernandes. L. C.; Krüger, C. E.; Motzafi-Haller, W. 
Figura 7 - Dados do ano todo (a) e do período de verão (b) de Sde Boqer plotados sobre a carta bioclimática de Bogo et al. (1994)

(a)

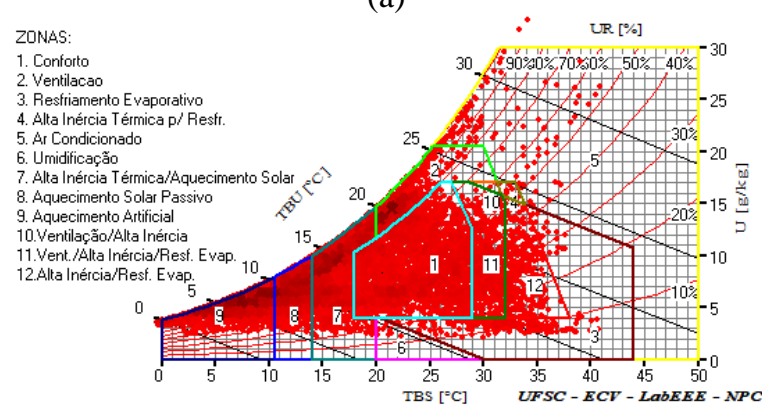

(b)

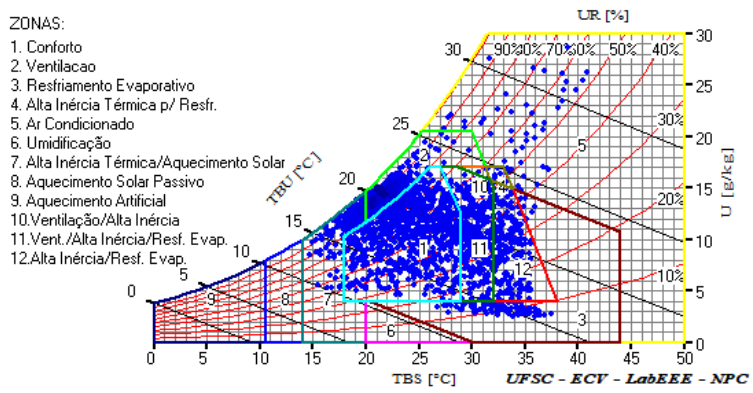

Tabela 2 - Estratégias bioclimáticas para o ano todo e para o período de verão em Sde Boqer (ano de 2006)

\begin{tabular}{l|c|c}
\hline \multicolumn{1}{c|}{ Estratégias } & $\begin{array}{c}\text { Porcentagem de tempo } \\
\text { em que a estratégia é } \\
\text { recomendada (\%) }\end{array}$ & $\begin{array}{c}\text { Porcentagem de tempo } \\
\text { em que a estratégia é } \\
\text { recomendada (\%) }\end{array}$ \\
\hline Conforto & 27,4 & 38,3 \\
Desconforto & 72,6 & 61,7 \\
Frio & 49,8 & 7,9 \\
Calor & 22,9 & 53,8 \\
Ventilação & 8,6 & 23,2 \\
Ventilação/alta inércia & 0,0 & 0,0 \\
Ventilação/alta inércia/resfriamento & 6,0 & 13,1 \\
evaporativo & 0,1 & 0,5 \\
Alta inércia térmica p/ resfriamento & 3,6 & 10,0 \\
Alta inércia/resfriamento evaporativo & 19,9 & 7,9 \\
Alta inércia térmica/aquecimento solar & 18,4 & 0,0 \\
Aquecimento artificial & 11,4 & 0,0 \\
Aquecimento solar passivo & 1,5 & 2,1 \\
Ar-condicionado & 2,9 & 5,0 \\
Resfriamento evaporativo & 0,1 & 0,0 \\
Umidificação & 46,2 & 88,9 \\
Sombreamento & & \\
\hline
\end{tabular}

Para uma análise focada no ambiente interno, a partir do TRY e do período monitorado com a CC, foram estimadas as temperaturas internas do ar $\left(T_{a}\right.$ in $)$ para a CC para todo o ano climático. A Figura 8 apresenta as temperaturas externas $\left(T_{a \text { ex }}\right)$ e internas plotadas juntamente com a faixa de temperaturas operativas recomendada pela EN 15251 (EUROPEAN..., 2007). A Figura 9 apresenta a plotagem considerando a faixa recomendada pela Standard 55 (AMERIAN..., 2017).

Diante das duas faixas de temperaturas operativas, as temperaturas do ambiente externo indicaram necessidade de aquecimento e resfriamento no período de verão e somente aquecimento no de inverno. As temperaturas externas também oscilam excessivamente, o que sugere que ambientes projetados para Sde Boqer devem ser dotados de alta inércia térmica.

Em se tratando das temperaturas estimadas para o ambiente interno da $\mathrm{CC}$, chama atenção a reduzida flutuação. A alta inércia térmica da edificação resultou em baixas amplitudes térmicas diárias, eliminando os picos de temperaturas e reduzindo a necessidade de resfriamento. No entanto, no caso do período de verão, principalmente quando considerada a norma Standard 55 (AMERICAN..., 2017), as temperaturas internas estimadas se situaram entre o limiar do desconforto por calor e a linha das temperaturas neutras. Em alguns momentos, avançaram para a situação de desconforto. Nesse contexto, estratégias para resfriamento são aplicáveis. Trata-se de um caso particularmente favorável ao TR, que, segundo pesquisas (GIVONI, 1984; GONZÁLEZ-CRUZ et al., 2014; KRÜGER; FERNANDES; LANGE, 2016), tem potencial para reduzir as temperaturas médias internas em aproximadamente $2{ }^{\circ} \mathrm{C}$. 
Figura 8 - $\mathbf{T}_{\mathbf{a} \text { in }}$ estimadas para a CC, $\mathbf{T}_{\mathbf{a} \text { ex }}$ do ano climático de referência e faixa de conforto segundo EN 15251

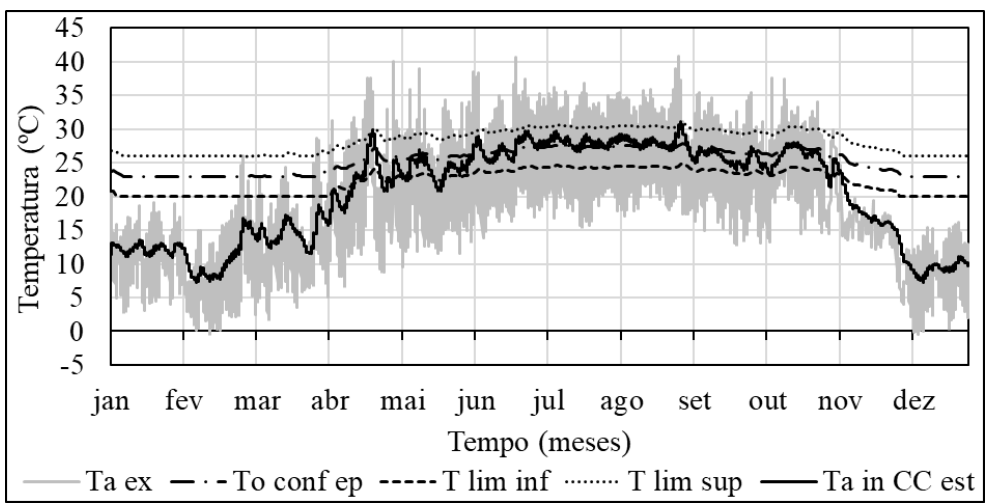

Figura 9 - $\mathbf{T}_{\mathbf{a}}$ in estimadas para a CC, $\mathbf{T}_{\mathbf{a}}$ ex do ano climático de referência e faixa de conforto segundo ASHRAE Standard 55

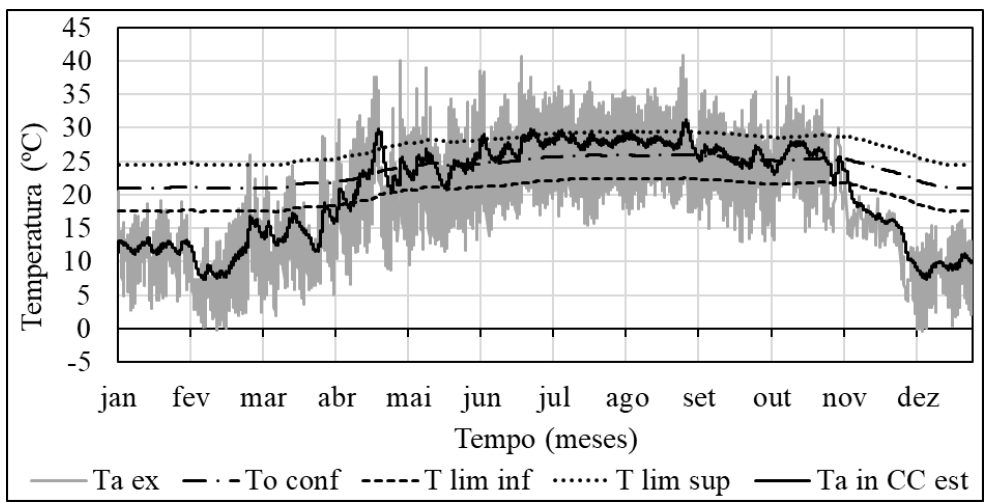

A Tabela 3 apresenta resumos quantitativos dos resultados apresentados de forma gráfica anteriormente (Figuras 8 e 9). Comparando os dados dos ambientes externo (medidos) e interno (estimados), para as duas normas, as temperaturas internas apresentaram menos horas em situação de desconforto, reflexo da inércia térmica da CC, ilustrada pelo valor médio de seu fator decremental, 0,058. A demanda por resfriamento foi reduzida, porém continuou existindo, o que justifica os experimentos com o teto-reservatório e painéis radiantes, principalmente com a norma Standard 55 (AMERICAN..., 2017).

\section{Análise do desempenho térmico das diferentes configurações}

Foram monitoradas oito diferentes configurações de cobertura, sendo seis caracterizadas como TR.

\section{Análise dos efeitos da alternância de configurações sobre as temperaturas internas do ar}

Durante o monitoramento da configuração de controle (CC), a média das temperaturas internas do ar ( $T_{\text {a in méd }}$ ) foi $2,16^{\circ} \mathrm{C}$ mais alta do que a média das temperaturas externas ( $T_{\text {a ex méd }}$ ) (Figura 10), resultando em CD igual a 0,41 . Esse sobreaquecimento do ambiente interno foi resultado da excessiva exposição à radiação solar, pois a configuração original não dispunha de elementos para sombreamento.

Quando instalada a configuração 2, dotada de elemento para sombreamento, ocorreu redução de 70,66\% do aquecimento ante a CC (Figura 11), reduzindo-se o CD médio para 0,12. A $T_{\text {a in méd }}$ foi $0,88^{\circ} \mathrm{C}$ mais alta do que a $T_{a \text { ex méd }}$ e $1,66{ }^{\circ} \mathrm{C}$ mais baixa do que a $T_{a}$ in méd estimada para a CC (referência). A redução das temperaturas internas comparativamente às registradas na $\mathrm{CC}$ mostrou que o sombreamento é fundamental para a redução do aquecimento do sistema, possibilitando que, quando instaladas as configurações dotadas de teto-reservatório, viesse a ocorrer resfriamento. 
Tabela 3 - Indicadores quanto ao conforto, desconforto e necessidade de aquecimento e resfriamento

\begin{tabular}{l|c|c|c|c}
\hline & \multicolumn{2}{|c|}{$\begin{array}{c}\text { Standard 55 } \\
\text { (AMERICAN..., 2017) }\end{array}$} & \multicolumn{2}{c}{ EN 15251 } \\
Indicadores & $\begin{array}{c}\text { Valores } \\
\text { considerando } \\
\text { as } \boldsymbol{T}_{\boldsymbol{a} \text { ex }} \text { do } \\
\text { TRY }\end{array}$ & $\begin{array}{c}\text { Valores } \\
\text { Considerando } \\
\text { as } \boldsymbol{T}_{\boldsymbol{a} \text { in }} \text { da } \\
\text { CC no TRY }\end{array}$ & $\begin{array}{c}\text { Valores } \\
\text { Considerando } \\
\text { as } \boldsymbol{T}_{\boldsymbol{a} \text { ex }} \text { do } \\
\text { TRY }\end{array}$ & $\begin{array}{c}\text { Valores } \\
\text { considerando } \\
\text { as } \boldsymbol{T}_{\boldsymbol{a} \text { in }} \text { da } \\
\text { CC no ano } \\
\text { TRY }\end{array}$ \\
\hline Horas em situação de conforto & $25,51 \%$ & $55,86 \%$ & 18,80 & 53,44 \\
\hline $\begin{array}{l}\text { Horas com necessidade de } \\
\text { resfriamento* }\end{array}$ & $14,05 \%$ & $2,96 \%$ & 10,95 & 0,22 \\
\hline $\begin{array}{l}\text { Horas com necessidade de } \\
\text { aquecimento** }\end{array}$ & $60,43 \%$ & $41,19 \%$ & 70,25 & 46,35 \\
\hline Graus hora resfriamento* & $3.846,38$ & 234,88 & $2.552,16$ & 3,20 \\
\hline Graus hora aquecimento** & $31.682,85$ & $19.403,97$ & $43.555,46$ & $27.132,78$ \\
\hline
\end{tabular}

Nota: *Temperatura base variável conforme o limite superior da faixa de conforto.

**Temperatura base variável conforme o limite inferior da faixa de conforto.

Figura 10 - Temperaturas externas e temperaturas internas medidas na CC

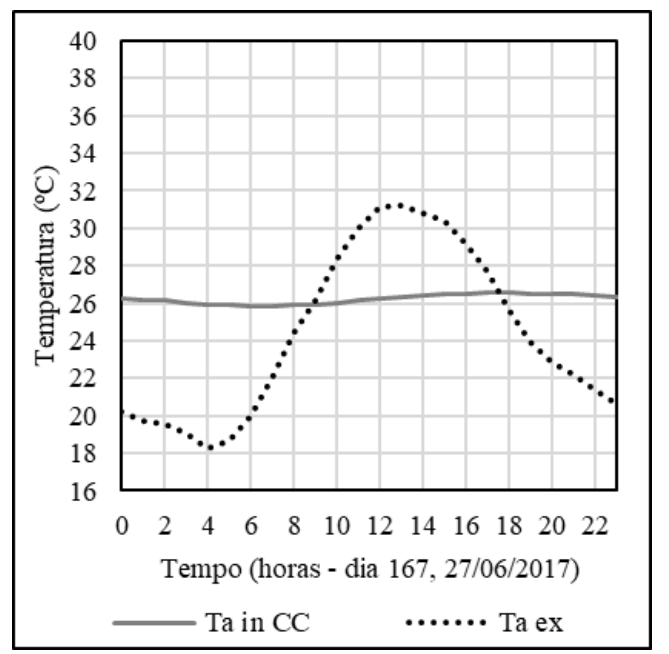

Figura 11 - Temperaturas externas, temperaturas internas medidas na C2 e temperaturas internas estimadas para a CC

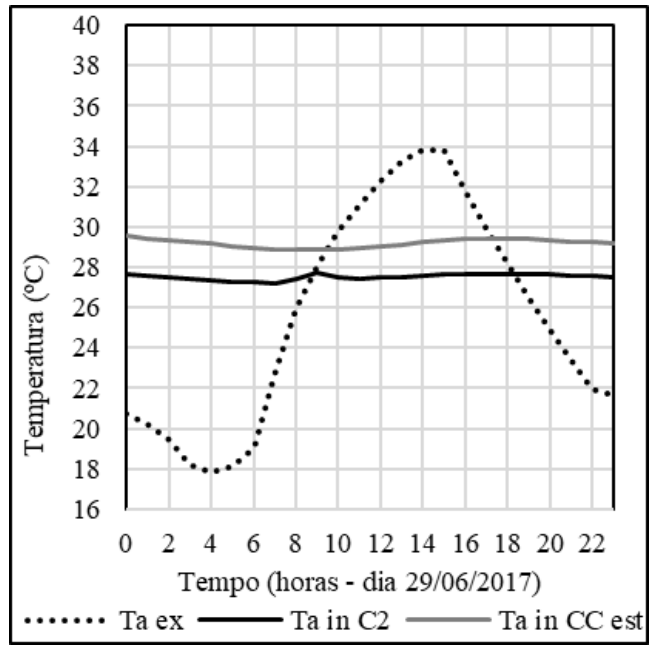


A configuração 3 apresentava sombreamento, TR exposto à evaporação e circulação forçada da água pelos painéis radiantes instalados internamente. Para além de reduzir o aquecimento, graças ao sombreamento, propiciou resfriamento efetivo (CD -0,138). A média das temperaturas internas $\left(T_{a}\right.$ in méd $)$ foi $1,07{ }^{\circ} \mathrm{C}$ mais baixa do que a média das temperaturas externas $\left(T_{\text {a ex méd }}\right)$ e $3,42{ }^{\circ} \mathrm{C}$ mais baixa do que a média das temperaturas internas $\left(T_{a \text { in méd }}\right.$ ) estimadas para a CC (Figura 12). No período de monitoramento dessa configuração, as $T_{\text {a ex méd }}$ foram levemente mais altas do que as dos outros períodos (Tabela 5), e a UR foi levemente mais baixa (Tabela 4). As condições favoráveis, associadas à grande superfície de água exposta à evaporação, potencializaram a eliminação do calor absorvido nas horas mais quentes do dia.

A configuração 4 se diferenciou da configuração 3 por apresentar uma camada de isolamento flutuante sobre a lâmina d'água, reduzindo a taxa de evaporação e as trocas térmicas por convecção com o ambiente externo. A adição desse elemento, que dificultou a eliminação de calor, repercutiu negativamente no sistema (Figura 13), resultando em desempenho similar ao da configuração original (CC). Em parte, o baixo desempenho também pode ser explicado pelo fato de que, no período do monitoramento dessa configuração, ocorreu UR externa relativamente mais alta (Tabela 4).

Na configuração 5 manteve-se a camada de isolamento flutuante. Porém, sobre essa camada foi instalado um sistema de spray, que era acionado durante o período noturno com o objetivo de potencializar o resfriamento evaporativo. Os resultados mostraram que o spray noturno apresentou efeito positivo relativamente à configuração 4, mas não foi suficientemente efetivo para eliminar o calor acumulado durante o dia (Figura 14). O desempenho foi inferior ao da configuração 3 e próximo ao da configuração 2 . Embora a $T_{a}$ in méd tenha resultado $2,8^{\circ} \mathrm{C}$ menor do que a da configuração de controle $(\mathrm{CC})$, continuou $0,6^{\circ} \mathrm{C}$ maior do que a $T_{a \text { ex méd }}$ no período, implicando um saldo de aquecimento $(\mathrm{CD}=1,32)$.

A configuração 6 (Figura 15), com spray acionado durante o dia todo, eliminou todo o calor acumulado, atingindo temperaturas internas médias semelhantes às médias externas. Porém, também não resultou em saldo de resfriamento.

Figura 12 - Temperaturas externas, temperaturas internas medidas na C3 e temperaturas internas estimadas para a CC

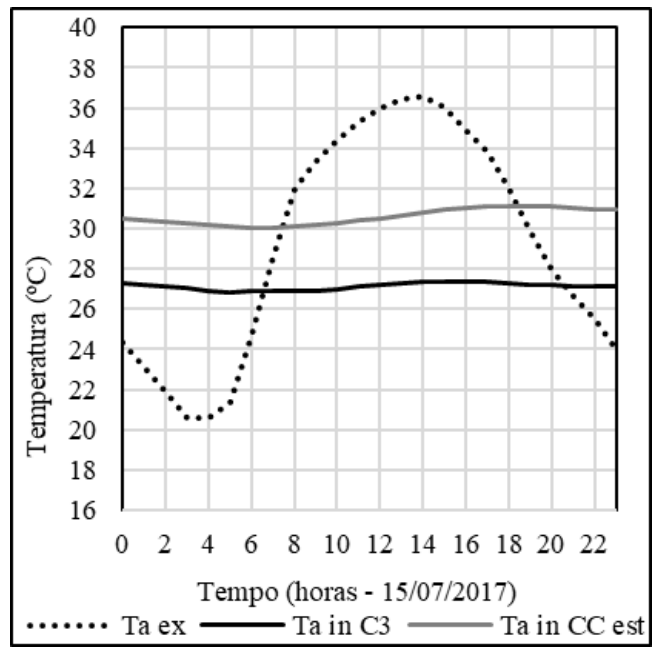

Tabela 4 - Médias da UR e da velocidade do ar do ambiente externo para os períodos de monitoramento

\begin{tabular}{l|c|c}
\hline \multicolumn{1}{c|}{ Período estável } & UR ex $(\boldsymbol{\%})$ & Va ex $(\mathbf{m} / \mathbf{s})$ \\
\hline Configuração controle (CC) & 59,84 & 3,33 \\
Configuração 2 & 51,52 & 2,88 \\
Configuração 3 & 50,50 & 3,25 \\
Configuração 4 & 65,44 & 3,34 \\
Configuração 5 & 64,21 & 3,81 \\
Configuração 6 & 61,57 & 2,99 \\
Configuração 7 & 68,37 & 3,42 \\
Configuração 8 & 63,09 & 2,91 \\
\hline
\end{tabular}

370 Fernandes. L. C.; Krüger, C. E.; Motzafi-Haller, W. 
Figura 13 - Temperaturas externas, temperaturas internas medidas na C4 e temperaturas internas estimadas para a CC

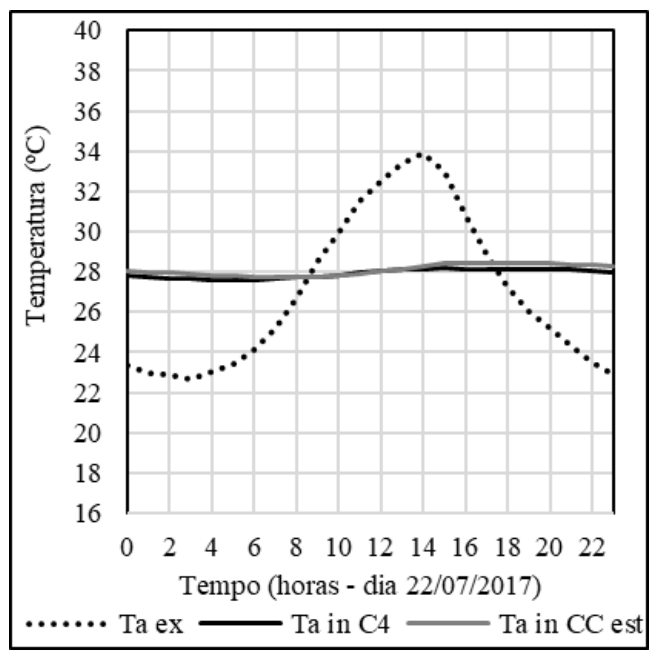

Figura 14 - Temperaturas externas, temperaturas internas medidas na C5 e temperaturas internas estimadas para a CC

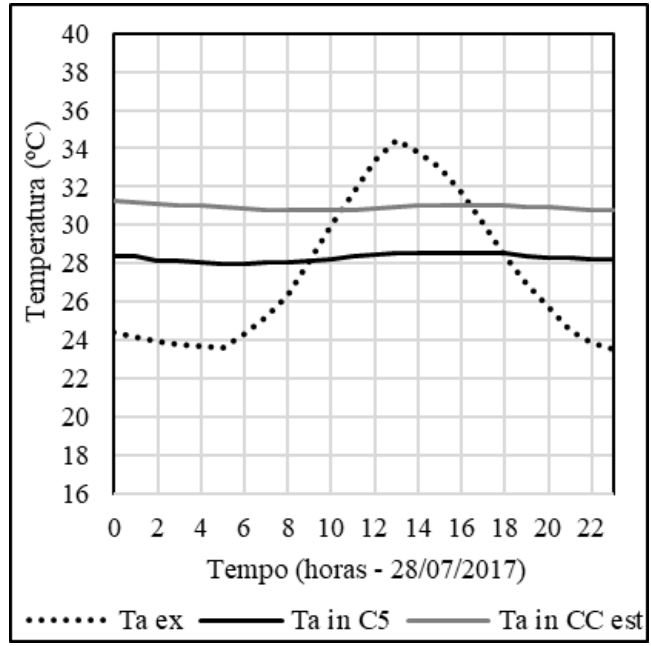

Figura 15 - Temperaturas externas, temperaturas internas medidas na $\mathrm{C} 6$ e temperaturas internas estimadas para a CC

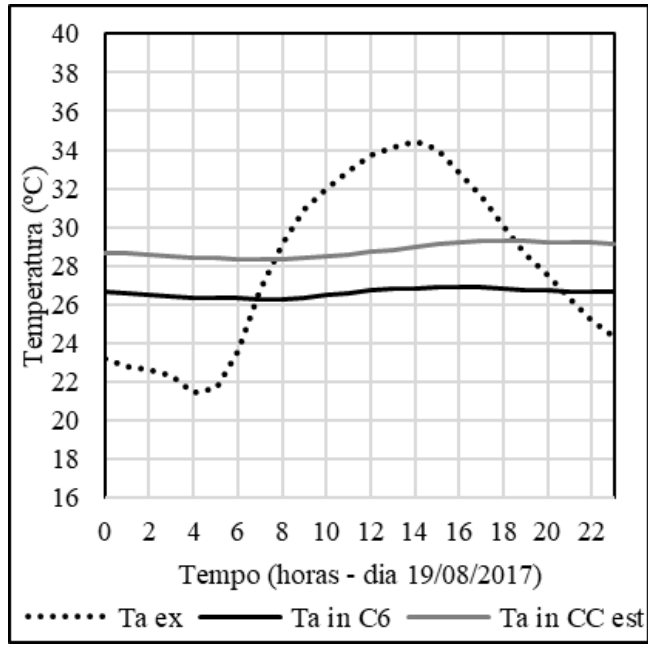


A adição do isolamento flutuante foi prejudicial ao sistema. Se, por um lado, reduziu os ganhos de calor devidos à radiação solar e à convecção durante o período diurno, por outro, impediu a evaporação durante todo o dia e reduziu as trocas térmicas durante o período noturno (quando as temperaturas externas eram menores do que as internas).

Na configuração 7 (Figura 16) manteve-se o isolamento flutuante e o spray funcionando durante o dia todo. Porém, foi desativada a circulação forçada de água do reservatório para os painéis radiantes, para avaliar se essa circulação resultava em efeito perceptível. A desativação da circulação d'água resultou em $T_{a}$ in méd $0,85^{\circ} \mathrm{C}$ mais alta do que a externa e em um saldo de aquecimento $(\mathrm{CD}=0,14)$. Comparativamente à configuração 6 (com circulação forçada), também houve aumento de temperatura $\left(0,8{ }^{\circ} \mathrm{C}\right)$, ou seja, a circulação d'água através dos painéis radiantes desempenhou um papel positivo no resfriamento do ambiente de testes. Os painéis radiantes à base de água potencializam as trocas térmicas do sistema, comprovando a hipótese apresentada na introdução deste artigo.

A última configuração testada foi a configuração 8, sem isolamento flutuante, mas com sprays e circulação d'água entre o reservatório e os painéis radiantes continuamente. Essa configuração diferia da configuração 3 por apresentar os sprays. Ao testá-la, buscou-se verificar se os sprays aumentariam as taxas de evaporação a ponto de melhorar o desempenho do sistema. Os resultados indicaram um saldo de resfriamento (Figura 17), porém inferior ao apresentado pela configuração 3. O desempenho inferior pode ser explicado parcialmente pelas condições ambientais externas: no período, a $T_{a \text { ex méd }}$ foi $2{ }^{\circ} \mathrm{C}$ menor que a verificada quando testada a configuração 3 , e a UR foi $25 \%$ maior, dificultando a evaporação. A $v_{a}$ externa também foi levemente inferior. A contribuição do sistema de sprays foi reduzida, pois, quando a água foi borrifada diretamente sobre o reservatório, à curta distância, quase não houve acréscimo na área exposta à evaporação, diferindo do que ocorreu na configuração 6, em que a água era borrifada sobre a superfície flutuante e ali permanecia algum tempo, evaporando.

\section{Análise do desempenho quanto ao aquecimento e ao resfriamento relativos e absolutos}

Para uma análise mais geral, esta subseção apresenta um resumo dos dados apresentados na subseção anterior.

Observando o CD (aquecimento/resfriamento relativo), cinco configurações $(1,2,4,5$ e 7) resultaram em aquecimento. A configuração 6 não resultou nem em aquecimento, nem em resfriamento $(C D=0,027)$. Somente duas configurações (3 e 8) resultaram em resfriamento, objetivo desta pesquisa.

Para estimar a redução média das $T_{a}$ in propiciada por cada configuração em relação à CC, foram estimadas as temperaturas internas horárias da CC para os períodos monitorados das demais configurações, obtendo-se o aquecimento/resfriamento médio, em graus Celsius. A configuração 3 apresentou a maior redução das temperaturas internas médias em relação à $\mathrm{CC}\left(-3,42^{\circ} \mathrm{C}\right)$. Também apresentou o maior resfriamento relativo $(\mathrm{CD}=-0,14)$ (Figura 18).

O resultado obtido com a configuração 3 foi produto da soma de diferentes estratégias:

(a) sombreamento (para a redução do aquecimento); e

(b) painéis radiantes acoplados ao teto-reservatório exposto à evaporação (para a obtenção de resfriamento).

A Figura 19 apresenta, para cada configuração, os valores do CD e a diferença entre as temperaturas médias internas e externas. Destacam-se os resultados para as configurações CC e 3 (maiores diferenças positiva e negativa em relação às médias das temperaturas externas).

A Tabela 5 apresenta os seguintes indicadores de desempenho:

(a) CD médio;

(b) médias das temperaturas internas e externas;

(c) diferenças entre as médias das temperaturas internas e externas; e

(d) diferenças médias entre as temperaturas estimadas da configuração CC e as das demais configurações.

Todas as configurações de TR, mesmo as menos eficientes, geraram condições ambientais internas melhores do que as geradas pela cobertura original comparativamente às condições externas. No entanto, o simples sombreamento da cobertura (configuração 2) propiciou condições superiores às das configurações 4 e 7, ou seja, a aplicação do TR ao projeto de edificações demanda uma análise prévia criteriosa de sua configuração. No contexto da pesquisa aqui apresentada, ficaram claras as contribuições positivas do sombreamento (para

372 Fernandes. L. C.; Krüger, C. E.; Motzafi-Haller, W. 
minimizar o aquecimento), do resfriamento evaporativo e dos painéis radiantes (para o resfriamento). Por outro lado, a camada de isolamento flutuante se mostrou prejudicial ao sistema, pois restringiu o resfriamento evaporativo.

Figura 16 - Temperaturas externas, temperaturas internas medidas na C7 e temperaturas internas estimadas para a CC

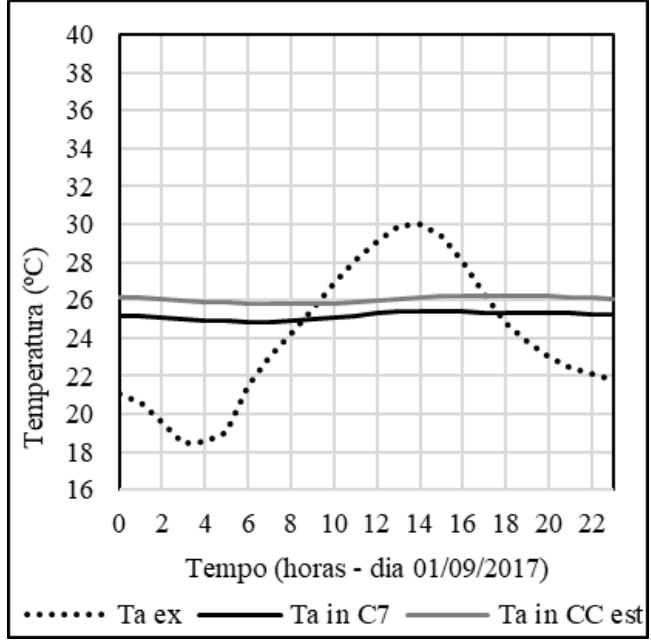

Figura 17 - Temperaturas externas, temperaturas internas medidas na C8 e temperaturas internas estimadas para a CC

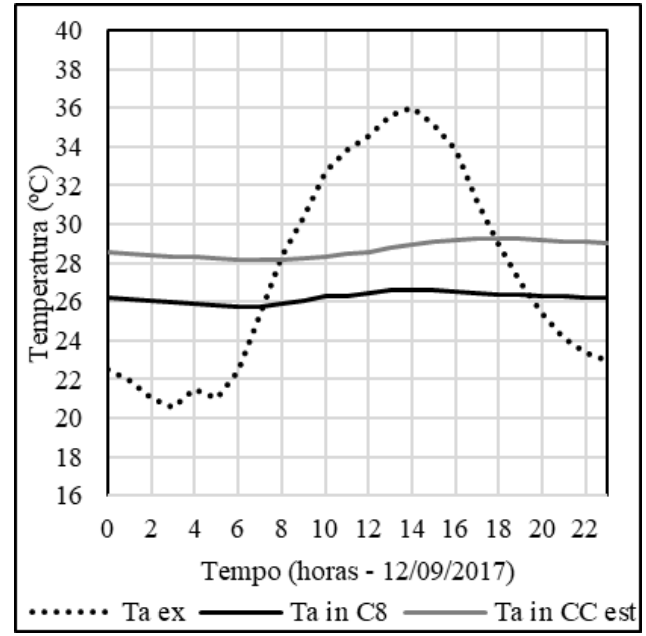

Figura 18 - CD e redução das temperaturas internas em relação à temperatura média interna da CC

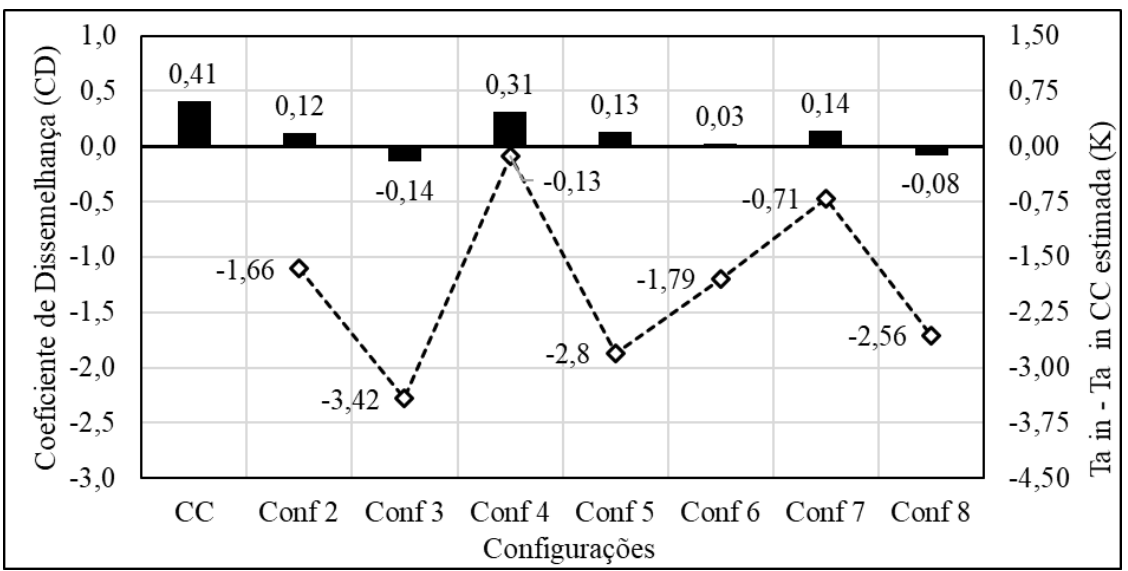

Experimentos de campo com teto-reservatório e painéis para resfriamento radiante em uma edificação-teste 
Figura 19 - CD e diferença entre as temperaturas médias internas e externas

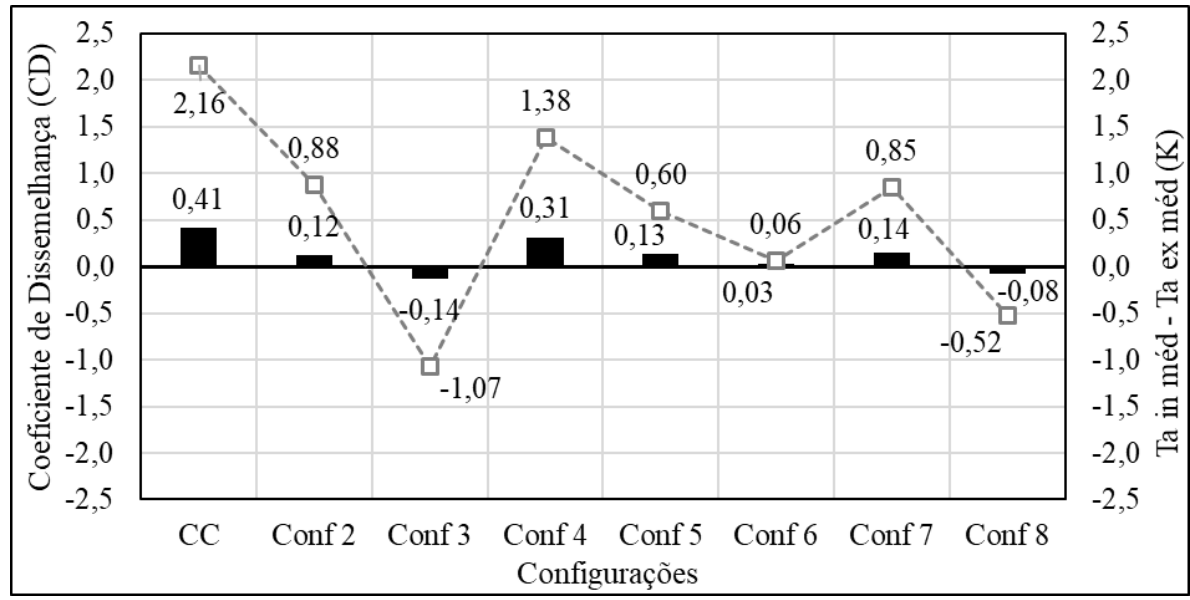

Tabela 5 - Indicadores de desempenho para as diferentes configurações

\begin{tabular}{l|c|c|c|c|c}
\hline Período estável & $\boldsymbol{C D}$ médio & $\boldsymbol{T}_{\boldsymbol{a} \text { in méd }}$ & $\boldsymbol{T}_{\boldsymbol{a} \text { ex méd }}$ & $\boldsymbol{T}_{\boldsymbol{a} \text { in méd }}-\boldsymbol{T}_{\boldsymbol{a} \text { ex méd }}$ & $\boldsymbol{T}_{\boldsymbol{a} \text { in méd }}-\boldsymbol{T}_{\boldsymbol{a} \text { in méd }}$ da CC \\
\hline $\begin{array}{l}\text { Configuração } \\
\text { Controle (CC) }\end{array}$ & 0,409 & 26,46 & 24,30 & $2,16 \mathrm{~K}$ & - \\
\hline Configuração 2 & 0,120 & 27,30 & 26,42 & $0,88 \mathrm{~K}$ & $-1,66 \mathrm{~K}$ \\
\hline Configuração 3 & $-0,138$ & 27,27 & 28,35 & $-1,07 \mathrm{~K}$ & $-3,42 \mathrm{~K}$ \\
\hline Configuração 4 & 0,314 & 27,93 & 26,55 & $1,38 \mathrm{~K}$ & $-0,13 \mathrm{~K}$ \\
\hline Configuração 5 & 0,132 & 28,39 & 27,79 & $0,60 \mathrm{~K}$ & $-2,80 \mathrm{~K}$ \\
\hline Configuração 6 & 0,027 & 27,07 & 27,01 & $0,06 \mathrm{~K}$ & $-1,79 \mathrm{~K}$ \\
\hline Configuração 7 & 0,144 & 25,80 & 24,95 & $0,85 \mathrm{~K}$ & $-0,71 \mathrm{~K}$ \\
\hline Configuração 8 & $-0,079$ & 26,19 & 26,71 & $-0,52 \mathrm{~K}$ & $-2,56 \mathrm{~K}$ \\
\hline
\end{tabular}

\section{Análise das relações entre as temperaturas superficiais e do ar nas configurações CC e C3}

As Figuras 20 e 21 apresentam as temperaturas superficiais $\left(T_{s}\right)$ e as temperaturas do ar $\left(T_{a}\right.$ in $)$ no interior do ambiente de testes, em diferentes alturas e superfícies, quando com a CC (dia 17 de junho) e com configuração 3 (dia 15 de julho).

A $T_{\text {a in }}$ a 0,6 m apresenta padrões de comportamento semelhantes nas duas configurações: baixa amplitude e forma semelhante nos gráficos. No entanto, percebem-se diferenças quando observadas as demais temperaturas.

$\mathrm{Na} \mathrm{CC}$, as $T_{S}$ do teto flutuaram de modo mais expressivo, com os valores máximos por volta das 20h30, o que implicou temperaturas radiantes médias $\left(T_{r m}\right)$ relativamente mais altas durante parte da noite. Por outro lado, quanto menor a altura do sensor da $T_{a}$ in, mais baixos os valores registrados. Ainda, as $T_{s}$ apresentaram valores relativamente próximos dos das $T_{a \text { in }}$.

$\mathrm{Na}$ configuração 3 , as $T_{a}$ in apresentaram diferenças menos expressivas entre si conforme a altura comparativamente à configuração de controle. Quanto às $T_{s}$ do teto e dos painéis radiantes, apresentaram valores mais baixos que os das $T_{a}$ in e menos oscilação em torno de seus valores médios. Como resultado, obteve-se um ambiente termicamente mais estável.

A inserção da variável $T_{a \text { ex }}$ na análise facilita o entendimento do comportamento das $T_{s}$ e $T_{a \text { in }}$ das duas configurações. Fica evidente que a $T_{a}$ in foi fortemente impactada pela $T_{s}$ do teto tanto na CC quanto na configuração 3 (Figuras 22 e 23). Na CC, a $T_{s}$ do teto eleva a $T_{a}$ in para patamar acima das temperaturas médias externas. Por sua vez, a $T_{s}$ do teto parece ser fortemente influenciada pela temperatura externa (e pela radiação solar, obviamente).

Na configuração 3, a $T_{s}$ do teto impacta a $T_{a \text { in }}$, reduzindo seus valores para abaixo da média da temperatura externa. Por outro lado, devido ao efeito do resfriamento evaporativo, parece haver certa independência entre as $T_{s}$ do teto e do ambiente externo. A $T_{s}$ do teto não oscila da mesma forma que a temperatura externa e apresenta valores médios mais baixos. Resumindo, o TR impactou significativamente os padrões das $T_{s}$, 
que, por sua vez, impactaram as $T_{a \text { in }}$ internas, resultando em maior equilíbrio térmico, em temperaturas internas médias mais baixas e em melhores condições ambientais para possíveis usuários.

Figura 20 - Temperaturas do ar e superficiais na CC - dia 17 de junho

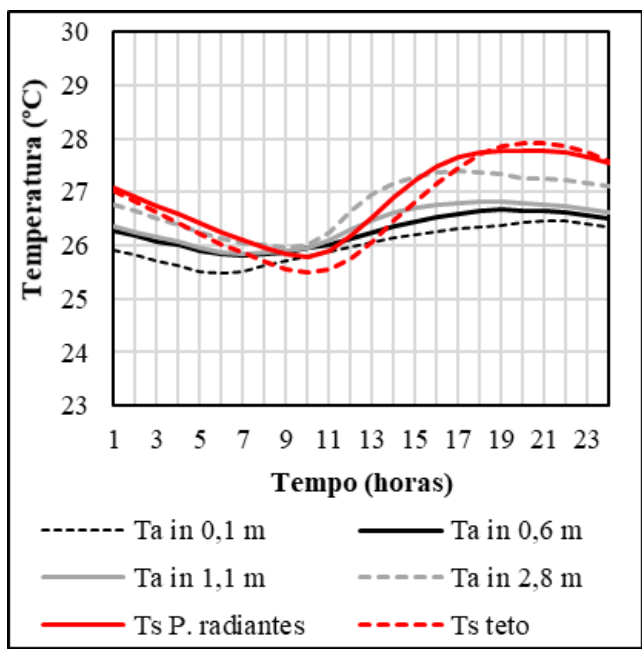

Figura 21 - Temperaturas do ar e superficiais na C3 - dia 15 de julho

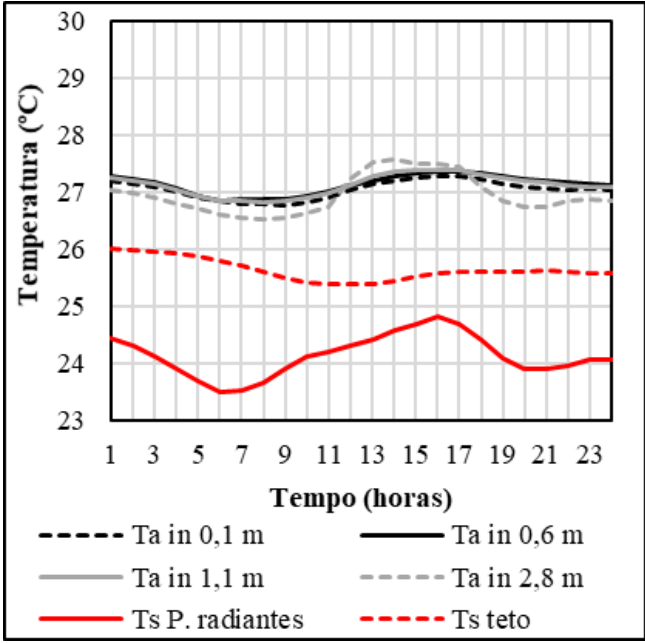

Figura 22 - Temperaturas internas e externas do ar e temperaturas superficiais da CC

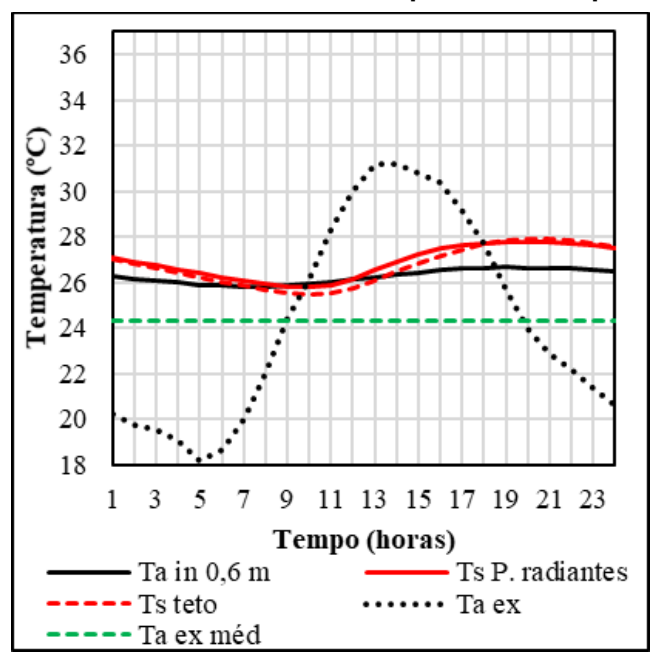


Figura 23 - Temperaturas internas e externas do ar e temperaturas superficiais da configuração 3

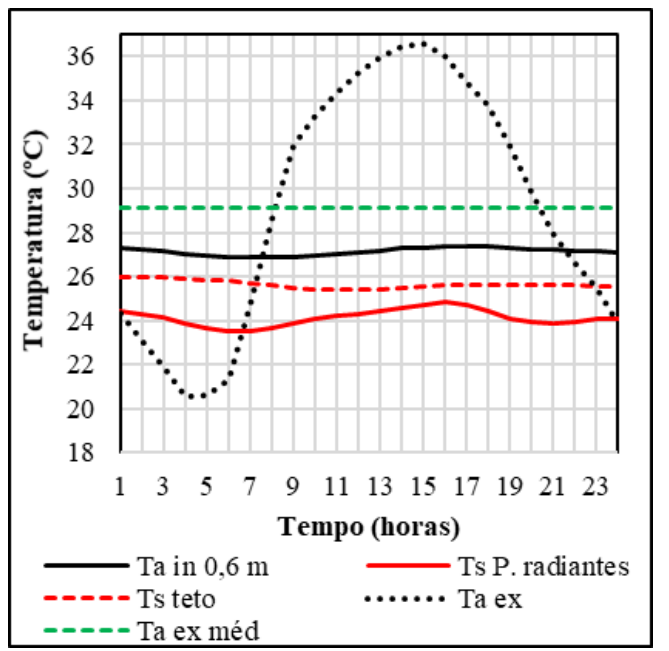

\section{Análise do desempenho quanto à estabilidade térmica}

Em todas as configurações, o ambiente interno mostrou-se resistente às flutuações térmicas do ambiente externo. A média da amplitude térmica diária permaneceu sempre abaixo de $1{ }^{\circ} \mathrm{C}$, e a máxima foi de apenas $1,38^{\circ} \mathrm{C}$, bem abaixo dos $7^{\circ} \mathrm{C}$ admissíveis se considerada a faixa com aceitabilidade para $80 \%$ da população proposta pela ASHRAE (Tabela 6). Tais valores contrastam com a média da amplitude térmica diária externa, que chegou a $15,08{ }^{\circ} \mathrm{C}$ (durante o monitoramento da configuração 2), e com a máxima, que atingiu $17,57^{\circ} \mathrm{C}$ (durante o monitoramento da configuração 3).

Tomando-se $7{ }^{\circ} \mathrm{C}$ como amplitude interna diária máxima admissível e a amplitude externa diária máxima do TRY de Sde Boqer, de 22,7 ${ }^{\circ} \mathrm{C}$, conforme discutido na seção Procedimentos Metodológicos, chegou-se ao valor de 0,31 , limite admissível para o $f$. Trata-se de um valor baixo, mas que se torna alto quando comparado com o $f$ máximo observado nas configurações testadas $(0,079)$.

A explicação para essa estabilidade térmica está nas características da edificação-teste: paredes internas pesadas, aberturas sombreadas, cores claras e envoltória pesada e isolada. Tais características fizeram com que as alterações nas configurações do TR se mostrassem pouco relevantes em relação à estabilidade da $T_{a \text { in }}$, impedindo o aprofundamento em relação a essa questão.

\section{Desempenho térmico ante as normas EN 15251 e Standard 55 e a carta bioclimática adaptada por Bogo et al. (1994)}

Nas subseções anteriores, compararam-se os resultados das diferentes configurações para determinar quais delas foram mais efetivas na obtenção de resfriamento e determinar os motivos dessa efetividade.

Nesta subseção, analisou-se o desempenho térmico das diferentes configurações diante dos parâmetros dados pelas normas EN 15251 e Standard 55 e pela carta bioclimática adaptada por Bogo et al. (1994). Essa análise visa produzir elementos para subsidiar a discussão sobre a aplicabilidade dos sistemas estudados em edificações convencionais.

Para essa análise, primeiramente, relacionaram-se os valores horários das $T_{o}$ com as $T_{a}$ in. Para isso, calcularam-se as $T_{r m}$ de hora em hora, do dia 30 de junho até o dia 23 de setembro (da configuração 2 até a 8), sem diferenciar as configurações. Comparando a $T_{r m}$ com a $T_{a \text { in }}$ (Figura 24), verificou-se $\mathrm{R}^{2}=0,992$. A diferença máxima entre as duas variáveis foi de $0,39^{\circ} \mathrm{C}$, e a diferença média foi de $0,11^{\circ} \mathrm{C}$. Dispondo-se dos valores horários da $T_{r m}$ e dos respectivos valores da $T_{a \text { in }}$, calcularam-se os valores para as $T_{o}$ para o mesmo período. Comparando-se as $T_{o}$ com as respectivas $T_{a \text { in }}$, verificou-se $\mathrm{R}^{2}=0,998$ (Figura 25). A diferença máxima entre essas duas variáveis foi de $0,19^{\circ} \mathrm{C}$, e a diferença média, de $0,06{ }^{\circ} \mathrm{C}$. A semelhança entre as variáveis possibilitou simplificar os procedimentos para avaliação do desempenho das configurações, substituindo a $T_{o}$ pela $T_{a}$ in ou seja, dispensou o cálculo da $T_{r m}$ e da $T_{o}$. 
Tabela 6 - Fator decremental e amplitudes térmicas diárias internas e externas das diferentes configurações

\begin{tabular}{|c|c|c|c|c|c|}
\hline Período estável & $\begin{array}{c}\text { Amp in méd } \\
\left({ }^{\circ} \mathrm{C}\right)\end{array}$ & $\begin{array}{c}\text { Amp in } \\
\text { máx }\left({ }^{\circ} \mathrm{C}\right)\end{array}$ & $\begin{array}{l}\text { Amp ex } \\
\text { méd }\left({ }^{\circ} \mathrm{C}\right)\end{array}$ & $\begin{array}{c}\text { Amp ex máx } \\
\left({ }^{\circ} \mathrm{C}\right)\end{array}$ & $f$ médio \\
\hline $\begin{array}{l}\text { Configuração } \\
\text { Controle (CC) }\end{array}$ & 0,75 & 1,04 & 13,06 & 17,57 & 0,058 \\
\hline Configuração 2 & 0,75 & 0,92 & 15,08 & 16,06 & 0,050 \\
\hline Configuração 3 & 0,69 & 0,90 & 14,12 & 17,54 & 0,049 \\
\hline Configuração 4 & 0,57 & 0,64 & 11,61 & 12,06 & 0,049 \\
\hline Configuração 5 & 0,97 & 1,38 & 12,34 & 13,47 & 0,079 \\
\hline Configuração 6 & 0,79 & 1,23 & 12,61 & 14,57 & 0,063 \\
\hline Configuração 7 & 0,62 & 0,90 & 11,67 & 14,09 & 0,053 \\
\hline Configuração 8 & 0,74 & 0,88 & 14,00 & 15,40 & 0,053 \\
\hline
\end{tabular}

Figura 24 - Temperatura radiante média versus temperatura interna do ar a 0,6 m

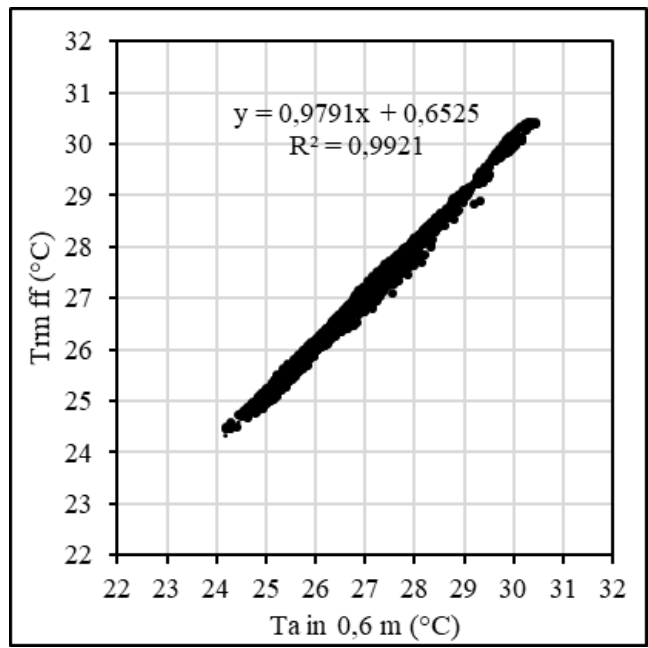

Figura 25 - Temperatura operativa versus temperatura interna do ar a 0,6 m

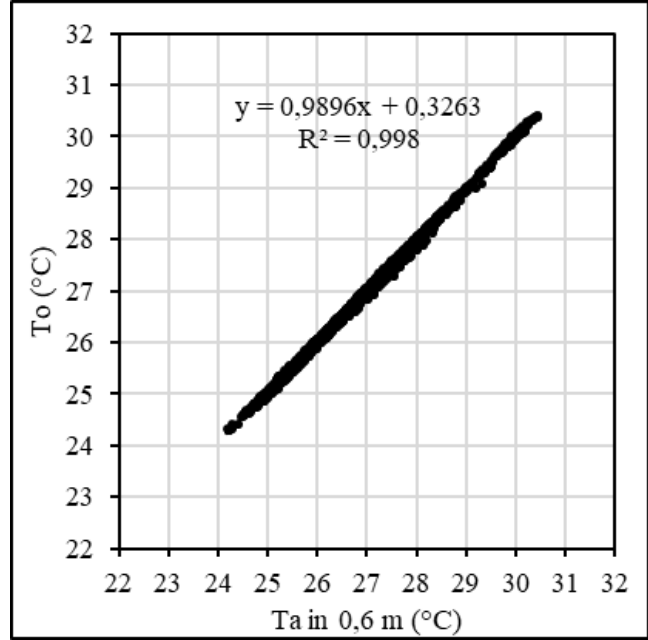

A Figura 26 apresenta dados de medições horárias para a $T_{a \text { ex }}$ e a $T_{a \text { in }}$ para o período de 10 de julho a 13 de setembro, para as configurações 3, 4, 5, 6, 7 e 8 (caracterizadas como TR). Também são apresentadas as $T_{a \text { in }}$ estimadas para a $\mathrm{CC}$ e a faixa de temperaturas operativas recomendada pela norma EN 15251 (EUROPEAN..., 2007). Todas as configurações de TR apresentaram desempenho térmico adequado em relação à faixa sugerida pela norma. Em geral, apresentaram temperaturas abaixo das $T_{\text {o conf }}$. A 
configuração 3 apresentou as maiores diferenças de temperatura em relação à CC. Todas as configurações dotadas de TR apresentaram $T_{a}$ in próximas das $T_{o \text { conf }}$, predominando temperaturas abaixo dessa linha de referência, a despeito do contexto climático de Sde Boqer. Tais resultados indicam que, no contexto climático de Sde Boqer, tendo em vista a EN 15251, o TR é uma tecnologia aplicável em habitações.

Embora mais larga, a faixa de temperaturas operativas dada pela Standard 55 (AMERICAN..., 2017) para Sde Boqer é menos tolerante a temperaturas altas (Figura 27). Ainda assim, todas as configurações de TR tenderam a apresentar $T_{a \text { in }}$ acima da linha central da faixa de conforto. As configurações 4 e 5 apresentaram temperaturas no limiar superior da faixa sugerida, mas se saíram melhores que a CC, que apresentou temperaturas mais altas que as do limite superior da faixa de conforto. Também em relação a esta norma, o TR apresentou desempenho adequado para utilização em edificações ocupadas.

Figura $26-T_{a}$ ex medidas, $T_{a \text { in }}$ medidas para as configurações 3 a $8, T_{a}$ in estimadas para a CC e faixa de conforto segundo a norma EN 15251

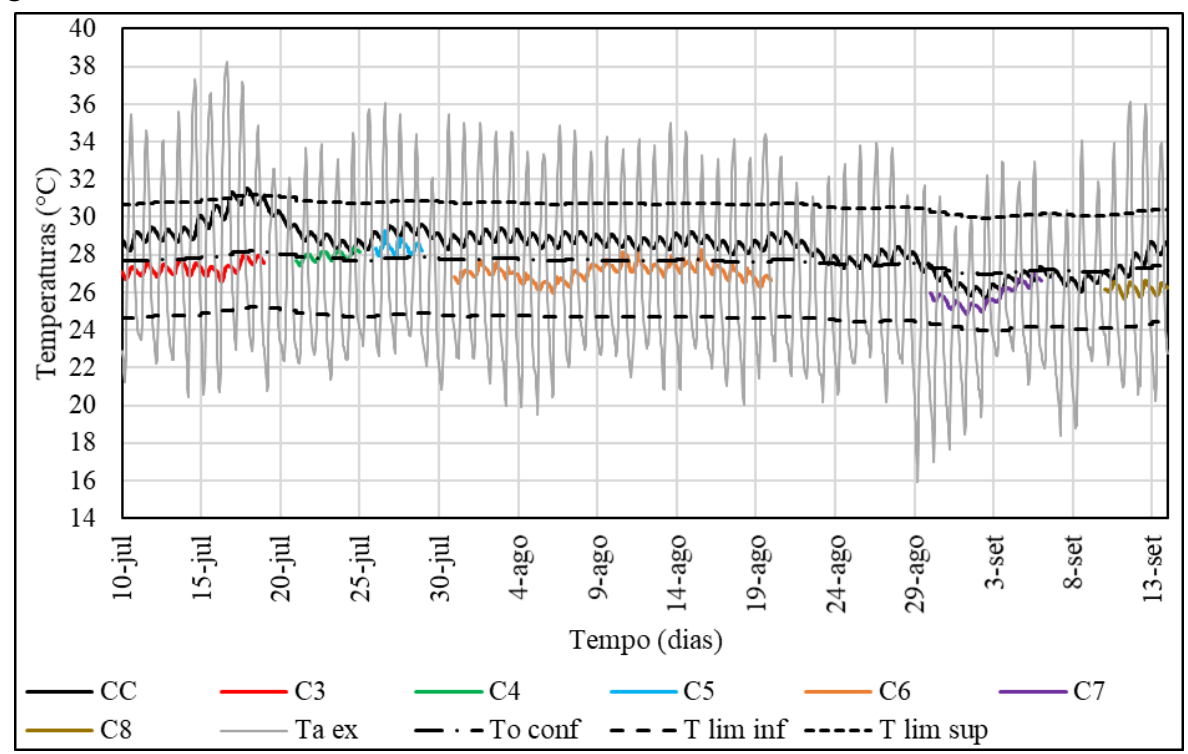

Figura 27 - $\mathrm{T}_{\mathrm{a} \text { ex }}$ medidas, $\mathrm{T}_{\mathrm{a} \text { in }}$ medidas para as configurações 3 a 8, $\mathbf{T}_{\mathrm{a}}$ in estimadas para a CC e faixa de conforto segundo a norma ASHRAE 55

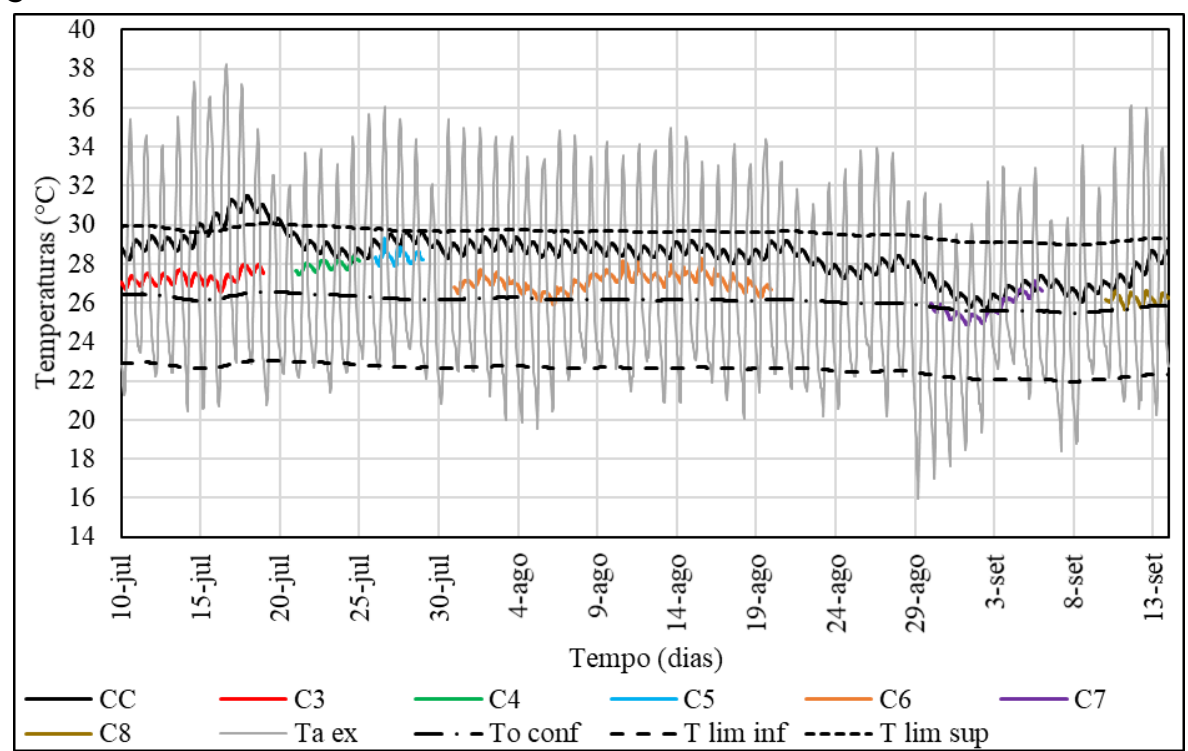

378 Fernandes. L. C.; Krüger, C. E.; Motzafi-Haller, W. 
A Figura 28 apresenta a plotagem dos dados dos períodos estáveis das diferentes configurações (incluindo as configurações CC e 2, que não se caracterizam como TR) sobre a carta bioclimática adaptada por Bogo et al. (1994). A maioria das configurações de TR apresentou condições internas entre confortáveis e levemente quentes. Pequenas alterações nos valores das variáveis ambientais internas poderiam fazer com que as condições passassem para desconfortáveis. A exceção foi a configuração 5, para a qual a carta indicou necessidade de aumentar a ventilação, ou seja, considerando esse instrumento de análise, os resultados foram predominantemente satisfatórios, mas com margem para melhorias.

Figura 28 - Plotagem de dados sobre a carta bioclimática adaptada por Bogo et al. (1994)

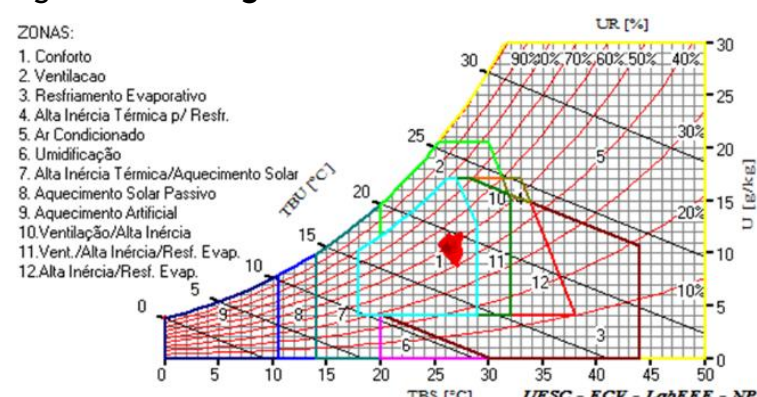

CC

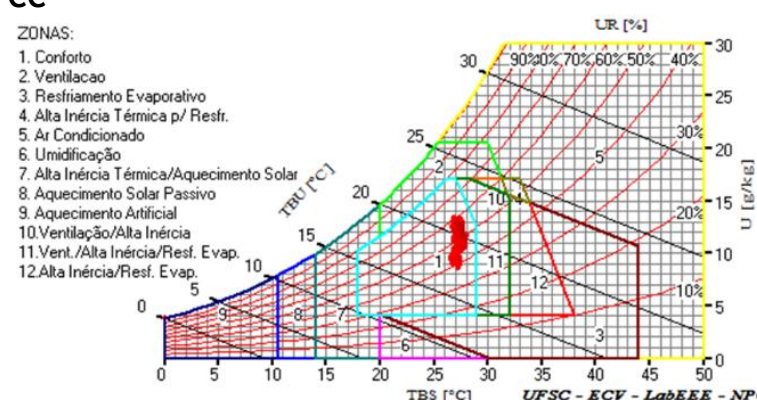

C3

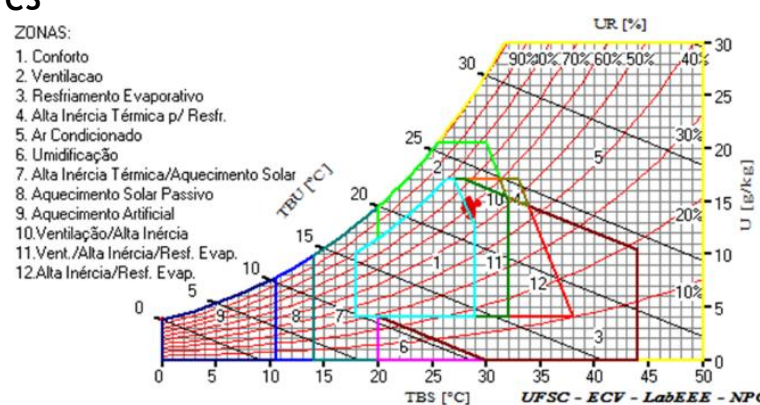

C5

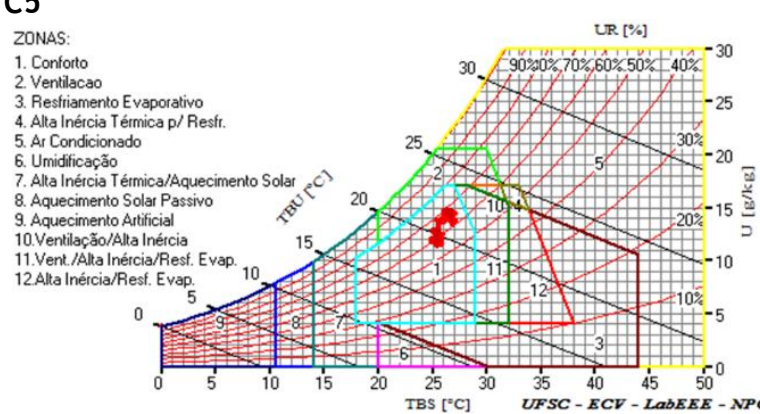

C7

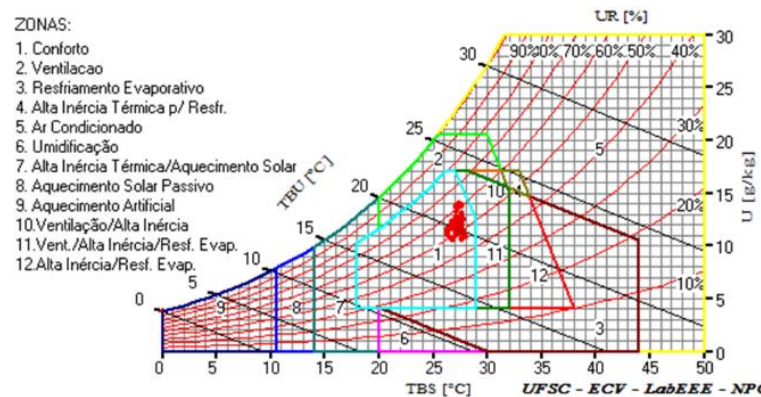

$\mathrm{C2}$

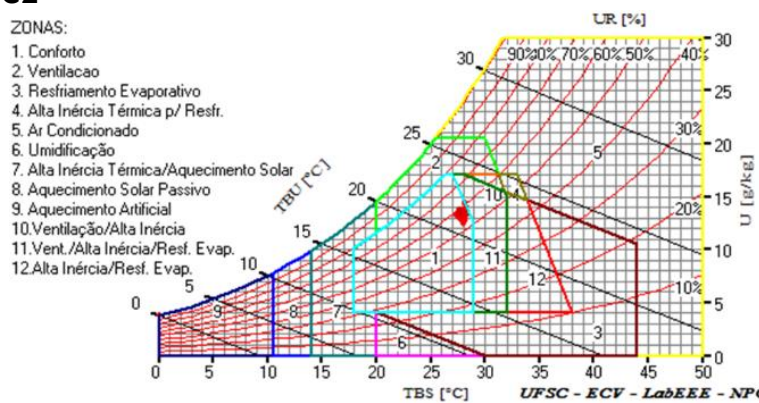

C4

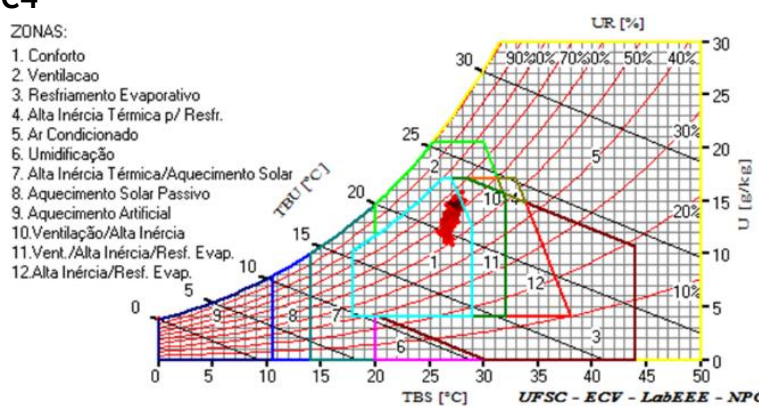

C6

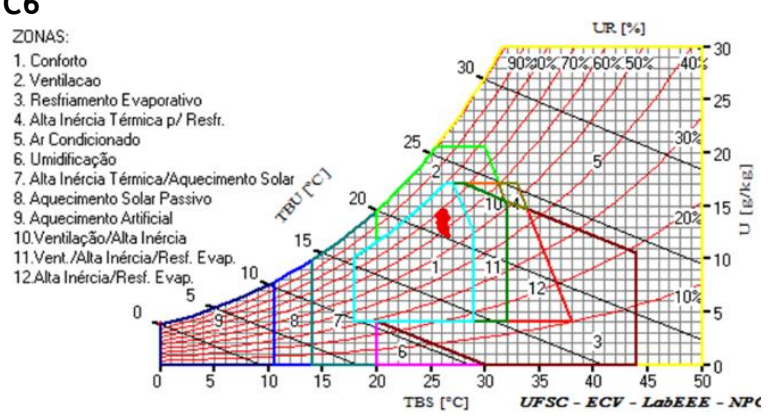

$\mathrm{C} 8$ 
A Tabela 7 apresenta um resumo das condições ambientais internas e externas para as diferentes configurações nos períodos de monitoramento segundo a carta bioclimática de Bogo et al. (1994). O monitoramento da maioria das configurações ocorreu em períodos nos quais predominaram condições externas desconfortáveis. No entanto, a maior parte das configurações apresentou $100 \%$ dos períodos com condições internas confortáveis; exceção para a configuração 5 , cujo período de monitoramento apresentou condições ambientais externas e internas predominantemente desconfortáveis. Como visto, o desempenho dessa configuração ficou comprometido por ela apresentar uma camada de isolamento flutuante, que dificultou as trocas térmicas, resultando em temperaturas internas excessivamente altas.

$\mathrm{O}$ valor médio das temperaturas internas do ar na configuração 5 foi $2,8^{\circ} \mathrm{C}$ mais baixo que o estimado para a configuração de controle (CC). Ainda assim, foi $0,6^{\circ} \mathrm{C}$ mais alto que a média das temperaturas externas no período, o que, em combinação com umidades relativas também altas, resultou em condições internas desconfortáveis quando considerado o diagrama de Bogo et al. (1994).

Por fim, é interesse relacionar os resultados deste experimento com os obtidos por outros autores que utilizaram resfriamento evaporativo, sombreamento e ventilação natural. Em se tratando de reservatórios de concreto, a redução de $3,4^{\circ} \mathrm{C}$ na média das temperaturas internas obtida com a configuração 3 neste experimento foi idêntica à obtida por Kharrufa e Adil (2007) em uma edificação na cidade de Bagdá. Porém, a diferença em relação às médias das temperaturas externas $\left(1,1^{\circ} \mathrm{C}\right)$ foi inferior à obtida por Givoni (1984) em Israel, em células-teste $\left(2^{\circ} \mathrm{C}\right)$.

Comparativamente aos reservatórios metálicos, a redução de $3,4{ }^{\circ} \mathrm{C}$ na média das temperaturas internas da edificação-teste, obtida com a configuração 3 , foi similar às reduções obtidas em experimentos com célulasteste em Maracaibo (3,6 $\left.{ }^{\circ} \mathrm{C}\right)$, (GONZÁLEZ-CRUZ; GONZÁLEZ-GARCIA, 2013), Florianópolis $\left(3,2^{\circ} \mathrm{C}\right)$ (GONZÁLEZ-CRUZ et al., 2014) e Curitiba (2,9 $\left.{ }^{\circ} \mathrm{C}\right)$ (FERNANDES, 2018).

\section{Conclusões}

O principal objetivo desta pesquisa foi avaliar o desempenho térmico de diferentes configurações de TR para resfriamento (com e sem painéis radiantes) aplicadas a uma edificação-teste no período de verão e em um clima com altas amplitudes térmicas diárias.

O melhor desempenho foi obtido com a configuração dotada de TR com resfriamento evaporativo, circulação forçada por painéis radiantes, sombreamento e ventilação natural do reservatório (configuração 3). A média das temperaturas internas foi $1,1^{\circ} \mathrm{C}$ menor do que a média das temperaturas externas e $3,4^{\circ} \mathrm{C}$ menor do que as temperaturas internas estimadas para a configuração original da edificação-teste.

$\mathrm{O}$ acionamento da circulação forçada pelos painéis radiantes reduziu a média das temperaturas do ar do ambiente de testes em $0,8^{\circ} \mathrm{C}$ em comparação à média quando não acionado, comprovando que a associação dos painéis radiantes ao teto-reservatório potencializa o efeito de resfriamento.

Tabela 7 - Condições ambientais internas e externas para as diferentes configurações nos períodos de monitoramento

\begin{tabular}{|c|c|c|c|c|c|c|c|c|}
\hline & \multicolumn{4}{|c|}{ Ambiente interno } & \multicolumn{4}{|c|}{ Ambiente externo } \\
\hline & $\begin{array}{c}\text { Conforto } \\
(\%)\end{array}$ & $\begin{array}{c}\text { Desconforto } \\
(\%)\end{array}$ & $\begin{array}{l}\text { Frio } \\
(\%)\end{array}$ & $\begin{array}{c}\text { Calor } \\
(\%)\end{array}$ & $\begin{array}{c}\text { Conforto } \\
(\%)\end{array}$ & $\begin{array}{c}\text { Desconforto } \\
(\%)\end{array}$ & $\begin{array}{l}\text { Frio } \\
(\%)\end{array}$ & $\begin{array}{c}\text { Calor } \\
(\%)\end{array}$ \\
\hline $\begin{array}{l}\text { Configuração } \\
\text { Controle (CC) }\end{array}$ & 100 & - & - & - & 54,8 & 45,2 & 17,1 & 28,1 \\
\hline Configuração 2 & 100 & - & - & - & 45,5 & 54,5 & 5 & 49,5 \\
\hline Configuração 3 & 100 & - & - & - & 35,9 & 64,1 & - & 64,1 \\
\hline Configuração 4 & 97 & 3 & - & 3 & 39,2 & 60,8 & - & 60,8 \\
\hline Configuração 5 & 21,9 & 78,1 & - & 78,1 & 27,4 & 72,6 & - & 72,6 \\
\hline Configuração 6 & 97,9 & 2,1 & - & 2,1 & 32,6 & 67,4 & - & 67,4 \\
\hline Configuração 7 & 100 & - & - & - & 39,6 & 60,4 & 10,7 & 49,7 \\
\hline Configuração 8 & 100 & - & - & - & 27,8 & 72,2 & - & 72,2 \\
\hline
\end{tabular}

380 Fernandes. L. C.; Krüger, C. E.; Motzafi-Haller, W. 
A redução nas temperaturas internas obtida com a configuração 3 em relação à configuração original foi semelhante às reduções obtidas em pesquisas utilizando células-teste com reservatórios metálicos (GONZÁLEZ-CRUZ; GONZÁLEZ-GARCIA, 2013; GONZÁLEZ-CRUZ et al., 2014; FERNANDES, 2018). No entanto, por serem experimentos com células-teste e realizados em diferentes contextos, para comparações precisas entre os sistemas são necessários experimentos específicos.

Os resultados desta pesquisa mostraram que o sombreamento do teto-reservatório, prevenindo o aquecimento devido à exposição à radiação solar direta, é uma medida fundamental para a efetividade do sistema. Comparativamente à configuração original (CC), a instalação do sombreamento (configuração 2) sobre a cobertura reduziu a temperatura média do ar em $1,7^{\circ} \mathrm{C}$, aproximadamente $50 \%$ da redução obtida com o sistema de painéis radiantes acoplados ao TR (configuração 3).

A adição de uma camada de isolamento flutuante sobre a lâmina d'água para reduzir os ganhos de calor devidos à incidência de radiação solar anulou a efetividade do sistema, pois reduziu a taxa de evaporação e as trocas térmicas com o ambiente externo.

A instalação de um sistema de sprays atuando sobre o isolamento flutuante, para gerar uma película d'água exposta à evaporação, possibilitou igualar a média das temperaturas internas à média das temperaturas externas, mas não resultou em resfriamento efetivo. Por outro lado, quando o sistema de sprays foi acionado diretamente sobre o reservatório, sem a camada flutuante, não produziu efeito perceptível.

O desempenho térmico das diferentes configurações também foi avaliado ante os parâmetros dados pelas normas EN 15251 (EUROPEAN..., 2007) e Standard 55 (AMERICAN..., 2017) e pela carta bioclimática adaptada por Bogo et al. (1994) com o objetivo de produzir elementos para subsidiar a discussão sobre a aplicação dos sistemas estudados em edificações convencionais. A maioria das configurações apresentou desempenho térmico adequado em relação às faixas de temperaturas operativas e de temperaturas e umidade do ar exigidos.

Por fim, o teto-reservatório não foi foco deste trabalho e cabem estudos sobre a possibilidade de utilização de água da chuva, o impacto do TR na estrutura e no custo das edificações, os procedimentos para manutenção relacionando o TR à realidade econômica brasileira, os efeitos da variação da profundidade da camada d'água e a aplicação do TR a uma edificação-teste ao longo do período de 1 ano, para melhor noção sobre a aplicabilidade do sistema.

\section{Referências}

AMERICAN SOCIETY OF HEATING, REFRIGERATING, AND AIR-CONDITIONING ENGINEERS. Standard 55: thermal environmental conditions for human occupancy. Atlanta, 2017.

AMERICAN SOCIETY OF HEATING, REFRIGERATING, AND AIR-CONDITIONING ENGINEERS. Handbook: Heating, Ventilating, and Air-Conditioning: Systems and Equipment. Atlanta, 2012.

BOGO, A. et al. Bioclimatologia aplicada ao projeto de edificações visando o conforto térmico. Florianópolis: UFSC, 1994. Relatório Interno - 02/94.

CHÁVEZ, J. R. G.; GIVONI, B.; MUNDET, S. Cooling by roof pond with floating insulation in the hot humid climate of Veracruz, Mexico. In: INTERNATIONAL CONFERENCE ON PASSIVE AND LOW ENERGY ARCHITECTURE, 24., Singapore, 2007. Proceedings [...] Singapore, 2007.

ERELL, E. et al. A passive cooling laboratory building for hot-arid zones. In: INTERNATIONAL CONFERENCE- ENERGY AND BUILDING IN MEDITERRANEAN AREA, 3., Thessaloniki, 1992. Proceedings [...] Thessaloniki, 1992.

ERELL, E.; KAFTAN, E.; MOTZAFI-HALLER, W. Daylighting for visual comfort and energy conservation in offices in sunny locations. Midreshet Ben Gurion: Israel Ministry of National Infrastructures, 2011. (Final research report).

ERELL, E.; YANNAS, S.; MOLINA, J. L. Roof cooling techniques: a design handbook. London: Earthscan, 2006.

EUROPEAN COMMITTEE FOR STANDARDIZATION. EN 15251: indoor environmental input parameters for design and assessment of energy performance of buildings addressing indoor air quality, thermal environment, lighting and acoustics. Brussels, 2007. 
FERNANDES, L. C. Experimentos de campo com teto-reservatório: desempenho térmico e percepção do usuário. Curitiba, 2018. Tese (Doutorado em Tecnologia e Sociedade) - Universidade Tecnológica Federal do Paraná, Curitiba, 2018.

FERNÁNDEZ-GONZÁLEZ, A.; COSTACHE, F. I. Cooling performance of a wet roofpond system in Las Vegas, Nevada. In: WORLD RENEWABLE ENERGY FORUM, Denver, 2012. Proceedings [...] Denver: C. Fellows, 2012.

FOSSATI, M. et al. Building energy efficiency: an overview of the Brazilian residential labeling scheme. Renewable and Sustainable Energy Reviews, v. 65, p. 1216-1231, 2016.

GIVONI, B. Indoor temperature reduction by passive cooling systems. Solar Energy, v. 85, n. 8, p. 16921726, 2011.

GIVONI, B. Options and applications of passive cooling. Energy and Buildings, v. 7, p. 297-300, 1984.

GONZÁLEZ-CRUZ, E. M. Estude de materiaux et de techniques du batiment pour la conception architecturale bioclimatique en climat chaud et humide. Paris, 1997. Tese de doutorado - Ecole des Mines de Paris, Paris, 1997.

GONZÁLEZ-CRUZ, E. M. et al. Estudo experimental com sistemas de resfriamento passivo em Florianópolis. In: ENCONTRO NACIONAL DE TECNOLOGIA DO AMBIENTE CONSTRUÍDO, 15. Maceió, 2014. Anais [....] Maceió: Antac, 2014.

GONZÁLEZ-CRUZ, E. M.; GONZÁLEZ-GARCIA, S. I. Estudio experimental sobre el comportamiento térmico de un nuevo tipo de techo-estanque para el enfriamiento pasivo en clima húmedo. Ambiente Construído, Porto Alegre, v. 13, n. 4, p. 149-171, out./dez. 2013.

GONZÁLEZ-CRUZ, E. M.; KRÜGER, E. L.; GIORDANO, D. E. Estudo da aplicabilidade de um sistema de resfriamento evaporativo indireto para otimização do conforto térmico em residências no território brasileiro. In: ENCONTRO NACIONAL DE TECNOLOGIA DO AMBIENTE CONSTRUÍDO, 15., Maceió, 2014. Anais [...] Maceió: Antac, 2014.

HYDE, R. Bioclimatic housing innovative designs for warm climates. Abingdon: Earthscan, 2008.

IMANARI, T.; OMORI, T.; BOGAKI, K. Thermal comfort and energy consumption of the radiant ceiling panel system: Comparison with the conventional all-air system. Energy and Buildings, v. 30, n. 2, p. $167-$ 175, 1999.

INTERNATIONAL ORGANIZATION FOR STANDARDIZATION. ISO 7726: ergonomics of the thermal environment: instruments for measuring physical quantities. Geneve, 1998.

ISRAEL METEOROLOGICAL SERVICE. Climate information. Bet-Dagan: IMS, 2007. Disponível em: http://www.ims.gov.il. Acesso em: 15 set. 2017.

KARMANN, C.; SCHIAVON, S.; BAUMAN, F. Thermal comfort in buildings using radiant vs. all-air systems: a critical literature review. Building and Environment, v. 111, p. 123-131, 2017.

KHARRUFA, S. N.; ADIL, Y. Roof pond cooling of buildings in hot arid climates. Building and Environment, v. 43, n. 1, p. 82-89, 2007.

KOTTEK, M. et al. World map of the Köppen-Geiger climate classification updated. Meteorologische Zeitschrift, v. 15, n. 3, p. 259-263, 2006.

KRÜGER, E. et al. Avaliação do potencial de resfriamento de um sistema teto-reservatório para condições subtropicais. Ambiente Construído, Porto Alegre, v. 16, n. 3, p. 107-125, jul./set. 2016.

KRÜGER, E. et al. Comparing occupant thermal perception of air conditioning and ceiling- mounted radiant cooling panels coupled to a roof pond. In: WINDSOR CONFERENCE: RETHINKING COMFORT, Windsor, 2018. Proceedings [...] Windsor, 2018.

KRÜGER, E. et al. Proposition of a simplified method for predicting hourly indoor temperatures in test cells. Ambiente Construído, Porto Alegre, v. 17, n. 3, p. 57-70, jul./set. 2017.

KRÜGER, E.; FERNANDES, L.; LANGE, S. Thermal performance of different configurations of a roof pond-based system for subtropical conditions. Building and Environment, v. 107, p. 90-98, 2016.

KRÜGER, E.; GONZÁLEZ-CRUZ, E.; GIVONI, B. Effectiveness of indirect evaporative cooling and thermal mass in a hot arid climate. Building and Environment, v. 45, n. 6, p. 1422-1433, 2010.

382 Fernandes. L. C.; Krüger, C. E.; Motzafi-Haller, W. 
LAMBERTS, R. Heat transfer through roofs of low cost Brazilian houses. Leeds, 1988. Thesis University of Leeds, Leeds, 1988.

LI, R. et al. Field evaluation of performance of radiant heating/cooling ceiling panel system. Energy and Buildings, v. 86, p. 58-65, 2015.

MEGGERS, F. et al. The Thermoheliodome: "air conditioning" without conditioning the air, using radiant cooling and indirect evaporation. Energy and Buildings, v. 157, p. 11-19, 2017.

MIRIEL, J.; SERRES, L.; TROMBE, A. Radiant ceiling panel heating-cooling systems: experimental and simulated study of the performances, thermal comfort and energy consumptions. Applied Thermal Engineering, v. 22, n. 16, p. 1861-1873, 2002.

NICOL, F.; HUMPHREYS, M. Derivation of the adaptive equations for thermal comfort in free-running buildings in European standard EN15251. Building and Environment, v. 45, n. 1, p. 11-17, 2010.

NICOL, F.; WILSON, M. An overview of the European Standard EN 15251. In: WINDSOR CONFERENCE 2010: ADAPTING TO CHANGE: NEW THINKING ON COMFORT, 6., Windsor, 2010. Proceedings [...] London: Network for Comfort and Energy Use in Buildings, 2010.

OVERBEY, D. The invention of the roofpond system. 2012. Disponível em: http://www.bdmd.com/theinvention-of-the-roofpond. Acesso em: 13 nov. 2019.

RHEE, K. N.; KIM, K. W. A 50-year review of basic and applied research in radiant heating and cooling systems for the built environment. Building and Environment, v. 91, p. 166-190, 2015.

ROMANA, F. et al. On the measurement of the mean radiant temperature and its influence on the indoor thermal environment assessment. Building and Environment, v. 63, p. 79-88, 2013.

RUBEL, F. et al. The climate of the European Alps: shift of very high resolution Köppen-Geiger climate zones 1800-2100. Meteorologische Zeitschrift, v. 26, n. 2, p. 115-125, 2017.

RUNSHENG, T.; ETZION, Y.; ERELL, E. Experimental studies on a novel roof pond configuration for the cooling of buildings. Renewable Energy, v. 28, n. 10, p. 1513-1522, 2003.

SHARIFI, A.; YAMAGATA, Y. Roof ponds as passive heating and cooling systems: a systematic review. Applied Energy, v. 160, p. 336-357, 2015.

SOLDOVIERI, T.; VILORIA, T. El Angulo Sólido y algunas de sus aplicaciones. Universidad del Zulia: Maracaibo, 2016.

SPANAKI, A.; TSOUTSOS, T.; KOLOKOTSA, D. On the selection and design of the proper roof pond variant for passive cooling purposes. Renewable and Sustainable Energy Reviews, v. 15, n. 8, p. 3523 3533, 2011 .

SZOKOLAY, S. Introduction to architectural science: the basis of sustainable design. $2^{\text {nd }}$. ed. Oxford: Elsevier, 2008.

TÉPOX, J. E. V.; GONZÁLEZ-CRUZ, E. M.; MATA, M. F. E. Cubiertas y estanques para optimizar el sistema pasivo de techo estanque metálico en clima cálido seco extremo: estudio experimental exploratorio. PALAPA, v. 3, p. 43-54, 2008.

TIWARI, G. N.; KUMAR, A.; SODHA, M. S. A review: cooling by water evaporation over roof. Energy Conversion and Management, v. 22, n. 2, p. 143-153, 1982.

\section{Agradecimentos}

Agradecimentos: ao Swiss Institute for Dryland Environmental \& Energy Research (SIDEER), Ben-Gurion University of the Negev, campus Sde Boqer, pela seção dos dados relativos ao ambiente externo; ao Bona Terra Department of Man in the Desert, Ben-Gurion University of the Negev, campus Sde Boqer, pelo empréstimo dos equipamentos e da edificação-teste; e à Coordenação de Aperfeiçoamento de Pessoal de Nível Superior (Capes), pelo apoio a esta pesquisa. 


\section{Leandro Carlos Fernandes}

Programa de Pós-Graduação em Engenharia Civil | Universidade Federal do Paraná | Rua Cel. Francisco H. dos Santos, $100,4^{\circ}$ andar, Jardim das Américas | Curitiba - PR - Brasil | CEP 81531-980 | Tel.: (41) 3361-3462 | E-mail: fernandes.ufpr@gmail.com

\section{Eduardo Leite Krüger}

Programa de Pós-Graduação em Engenharia Civil | Universidade Tecnológica Federal do Paraná | Av. Deputado Heitor de Alencar Furtado, 5000, Ecoville, Campus Curitiba - Sede Ecoville | Curitiba - PR - Brasil | CEP 81280-340 | Tel.: (41) 3279-4578 | E-mail: ekruger@utfpr.edu.br

\section{Wolfgang Motzafi-Haller}

Ben Gurion University of the Negev | Midreshet Ben Gurion, Israel | E-mail: womoha@post.bgu.ac.il

\section{Ambiente Construído}

Revista da Associação Nacional de Tecnologia do Ambiente Construído

$$
\text { Av. Osvaldo Aranha, } 99-3^{\circ} \text { andar, Centro }
$$

Porto Alegre - RS - Brasil

CEP $90035-190$

Telefone: +55 (51) 3308-4084

Fax: +55 (51) 3308-4054

www.seer.ufrgs.br/ambienteconstruido

E-mail: ambienteconstruido@ufrgs.br 